\title{
Q
}

\section{Stillbirths: Where? When? Why? How to make the data count?}

Joy E Lawn, Hannah Blencowe, Robert Pattinson, Simon Cousens, Rajesh Kumar, Ibinabo Ibiebele, Jason Gardosi, Louise T Day, Cynthia Stanton, for The Lancet's Stillbirths Series steering committee*

Lancet 2011; 377: 1448-63

Published Online

April 14, 2011

DOI:10.1016/S0140-

6736(10)62187-3

See Comment page 1386

See Comment Lancet 2011;

377: 1291

See Online/Comment

DOI:10.1016/S0140-

6736(10)62357-4,

DOI:10.1016/S0140-

6736(11)60099-8,

DOI:10.1016/S0140-

6736(11)60025-1, and

DOI:10.1016/S0140-

6736(11)60279-1

This is the second in a Series of

six papers about stillbirths

* Members listed at end of paper

Saving Newborn Lives/Save the

Children, Cape Town, South Africa (J E Lawn MRCP [Paeds]); Health Systems Research Unit, Medical Research Council, Cape Town, South Africa (J E Lawn); Institute of Child Health, London, UK (J E Lawn); London School of Hygiene and Tropical Medicine, London, UK (H Blencowe MRCPCH,

Despite increasing attention and investment for maternal, neonatal, and child health, stillbirths remain invisible-not counted in the Millennium Development Goals, nor tracked by the UN, nor in the Global Burden of Disease metrics. At least 2.65 million stillbirths (uncertainty range 2.08 million to 3.79 million) were estimated worldwide in 2008 ( $\geq 1000 \mathrm{~g}$ birthweight or $\geq 28$ weeks of gestation). $98 \%$ of stillbirths occur in low-income and middle-income countries, and numbers vary from 2.0 per 1000 total births in Finland to more than 40 per 1000 total births in Nigeria and Pakistan. Worldwide, $67 \%$ of stillbirths occur in rural families, $55 \%$ in rural sub-Saharan Africa and south Asia, where skilled birth attendance and caesarean sections are much lower than that for urban births. In total, an estimated 1.19 million (range 0.82 million to 1.97 million) intrapartum stillbirths occur yearly. Most intrapartum stillbirths are associated with obstetric emergencies, whereas antepartum stillbirths are associated with maternal infections and fetal growth restriction. National estimates of causes of stillbirths are scarce, and multiple $(>35)$ classification systems impede international comparison. Immediate data improvements are feasible through household surveys and facility audit, and improvements in vital registration, including specific perinatal certificates and revised International Classification of Disease codes, are needed. A simple, programme-relevant stillbirth classification that can be used with verbal autopsy would provide a basis for comparable national estimates. A new focus on all deaths around the time of birth is crucial to inform programmatic investment.

\section{Why don't stillbirths count?}

Stillbirths are invisible in many societies and on the worldwide policy agenda, but are very real to families who experience a death. Despite 30 years of attention to child survival interventions, ${ }^{1,2}$ more than 20 years of attention to safe motherhood,,$^{3,4}$ and increasing recent attention to survival of newborn babies, ${ }^{5-7}$ the focus worldwide has remained on survival after livebirth. Stillbirths remain mostly ignored, not counting on policy, programme, and investment agendas, both internationally and often also at the national level. ${ }^{8}$

Key messages

- Where? At least 2.65 million third-trimester stillbirths are estimated to occur every year, $98 \%$ in low-income and middle-income countries, and $55 \%$ in rural families in sub-Saharan Africa and south Asia where skilled attendance and caesarean sections are much lower than that for urban births. The stillbirth rate varies from 2.0 per 1000 total births reported in Finland to more than 40 per 1000 total births in Nigeria and Pakistan. Worldwide, $55 \%$ of all stillbirths occur in rural families in south Asia and sub-Saharan Africa.

- When? Worldwide, about 1.19 million stillbirths are estimated to occur during labour (intrapartum). Higher rates are estimated in low-income countries, where about half of stillbirths are term intrapartum babies, viable with better care during birth Antepartum stillbirths (1.46 million) need improved care during pregnancy, targeting maternal infections, hypertension, and poor fetal growth.

- Why? National and worldwide estimates for stillbirth causation and linked maternal conditions are impeded by more than 35 different classifications systems. Despite limitations in the available data, the main five to target for global stillbirth reduction are clear: childbirth complications; maternal infections in pregnancy; maternal conditions, especially hypertension; fetal growth restriction; and congenital abnormalities.

(Continues on next page)
The importance of neonatal deaths has risen on the worldwide policy agenda, mainly because of the Millennium Development Goals (MDGs) and recognition of the increasing proportion of child deaths that happen in the first month of life-from $37 \%$ in $2000^{7}$ to $41 \%$ in 2008. ${ }^{9}$ A baby who dies just after birth counts in the MDG tracking, but a baby who dies in the third trimester or even during labour does not. Neither the MDGs nor the Global Burden of Disease metrics mention stillbirths, and stillbirth data are not routinely compiled by the UN. Even when stillbirths are recorded in surveys, the data are frequently combined with early neonatal deaths and reported as perinatal mortality, a combination that reduces visibility and might mask reporting differences, systematic misclassification, variation in trends, and different solutions..$^{10}$

Stillbirths are not just a low-income country problem. Rates in the UK and USA have decreased by only $1 \%$ per year for the past 15 years and stillbirths now account for two-thirds of perinatal deaths in the UK. ${ }^{11-14}$ In high-income countries, stillbirths exceed deaths from sudden infant death syndrome by a factor of ten, ${ }^{15}$ but receive less attention in programmes and funding for research. ${ }^{8,14}$

The number of third-trimester stillbirths is slightly lower than the 3 million early neonatal deaths and is larger than the yearly number of all deaths caused by HIV/AIDS. ${ }^{16,17}$ This paradox of low policy attention despite the high burden, and irrespective of close links to other factors with policy momentum, raises an unaddressed question. Do the data deficits, absence of consensus for programme priorities, or paucity of advocates explain the attention gap, or are there other specific factors that limit attention to 
stillbirths? Shiffman's report ${ }^{18}$ on the political imperative for safe motherhood asked "Why do some global health initiatives receive priority from international and national political leaders, whereas others receive little attention?". In the first paper in The Lancet's Stillbirth Series, Frøen and colleagues ${ }^{8}$ adapted Shiffman's framework to study some of the factors that shape low visibility and political priority for stillbirths.

Data on and solutions for stillbirths need to be organised and communicated so that stillbirths are given the importance that their burden deserves in maternal, neonatal, and child health programmes, which received at least US $\$ 5.4$ billion in donor funding for $2008 .{ }^{19}$ Establishment of what to do in which context, and how, requires setting of data-based priorities in high-income and low-income countries. In this paper, we present epidemiological data to prioritise actions to reduce the numbers of stillbirths, especially in lowincome and middle-income countries, where most cases occur. Subsequent papers in this Series review the evidence for the effectiveness of different stillbirth interventions, ${ }^{20}$ how to integrate and implement these in low-income and middle-income countries, ${ }^{21}$ and highlight priorities for reducing the numbers of stillbirths in high-income countries. ${ }^{14}$

\section{Defining stillbirths}

Inconsistent use of terminology has contributed to confusion about stillbirths. ${ }^{8}$ The terminology has changed over time and, despite clear worldwide guidelines,

(Continued from previous page)

- Improving the data? Most stillbirths occur in countries without adequate vital registration. Urgent focus is needed to increase the quality of data on pregnancy outcomes collected through alternative data sources, especially household surveys, to count stillbirths, estimate causes (by use of a simple, programmatic classification that can be used with verbal autopsy), and improve coverage and tracking data for key maternal, neonatal, and stillbirth interventions.

- Change by 2020? The average yearly rate of reduction has been slower for stillbirths (estimated 1.1\% between 1995 and 2009) than for maternal and child mortality reductions. Without an acceleration of current progress, by 2020 more than $90 \%$ of all stillbirths will be in south Asia and sub-Saharan Africa. Stillbirths deserve more attention and should be specified in targets after the Millennium Development Goals. Every country should have national estimates of stillbirth rate and causes. The UN should collect stillbirth data, facilitate yearly estimates, and improve the 11th revision of the International Classification of Diseases for stillbirth and neonatal deaths. The Global Burden of Disease metrics should also include data on stillbirths.

there is much variation between countries, with greater variability in high-income countries than in lowincome countries..$^{22,23}$

The International Classification of Diseases, 10th revision (ICD-10) ${ }^{24}$ refers to fetal deaths, not stillbirths. Fetal death is defined as "death prior to the complete expulsion or extraction from its mother of a product of conception...the fetus does not breathe or show any other evidence of life, such as beating of the heart, pulsation of the umbilical cord, or definite movement of voluntary muscles". In ICD, the

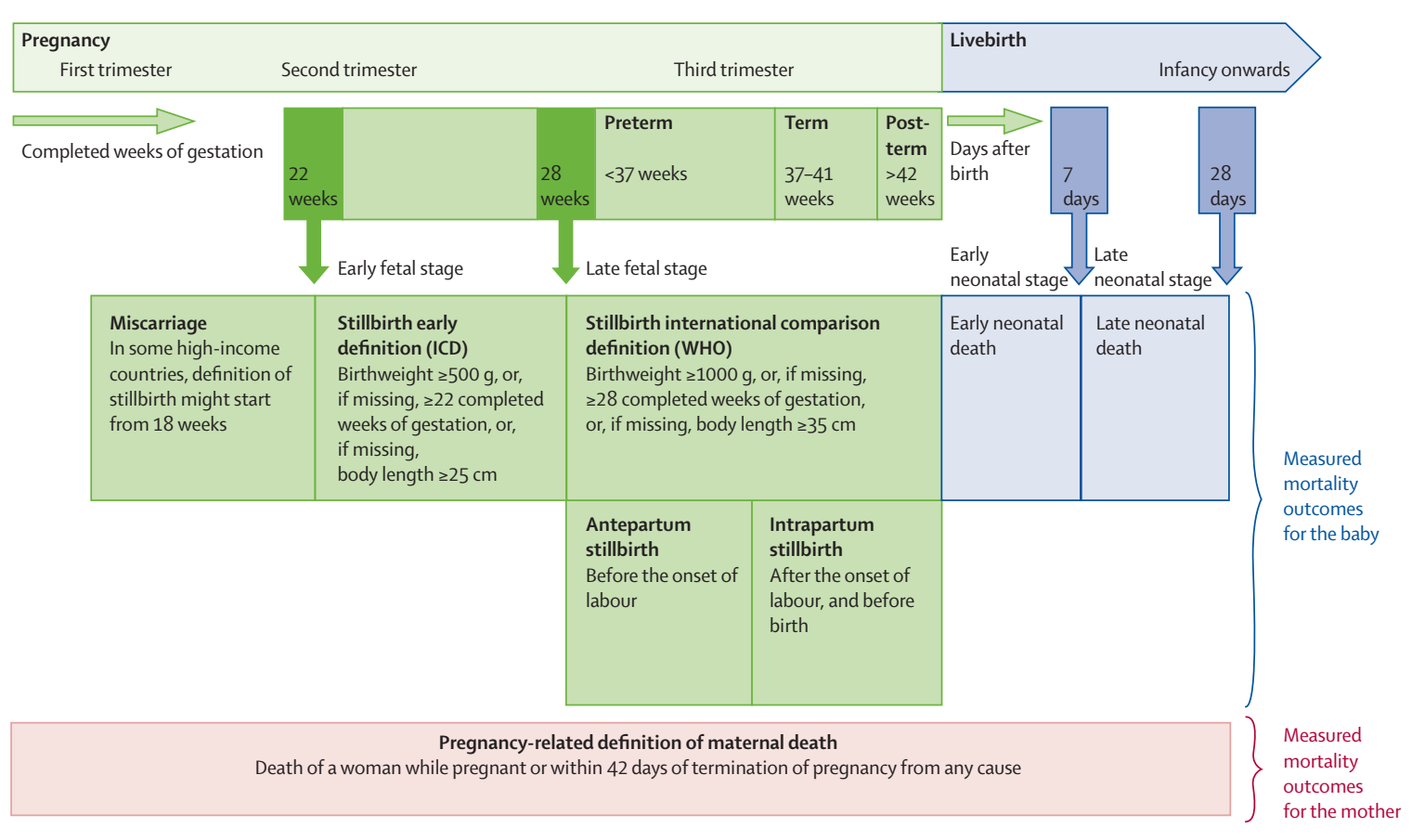

Figure 1: Defining stillbirths and associated pregnancy outcomes for international comparison Definitions from ICD, tenth revision. ICD=International Classification of Diseases.

Prof S Cousens DipMathStat) Medical Research Council Maternal and Infant Health Care Strategies Research Unit, Department of Obstetrics and Gynaecology, University of Pretoria, Pretoria, South Africa (Prof R Pattinson FCOG SA); Postgraduate Institute of Medical Education \& Research, Chandigarh, India (Prof R Kumar MD); Mater Medical Research Institute, Brisbane, QLD, Australia (I lbiebele MIPH); West Midlands Perinatal Institute, Birmingham, UK (ProfJ Gardosi FRCOG); LAMB Hospital, Parbatipur, Bangladesh (LT Day MRCOG); and Johns Hopkins Bloomberg School of Public Health, Baltimore, MD, USA (C Stanton PhD) Correspondence to: Dr Joy E Lawn, 11 South Way, Pinelands, Cape Town 7405, South Africa joylawn@yahoo.co.uk 
Panel: Sources of and limitations for data on stillbirths

\section{Stillbirth rate}

Inputs

Stillbirth data were identified through systematic searches and assessed according to specified inclusion criteria. More details are available elsewhere..$^{38}$ Vital registration or national stillbirth registries (79 countries), nationally representative surveys (predominantly demographic and health surveys -69 surveys from 39 countries), and studies identified through systematic searches (113 populations from 42 countries) were included.

\section{Modelling}

A regression model was developed to predict national stillbirth rates. Estimates were modelled for the years 1995-2009 for 129 countries without available, recent vital registration data, using national predictor covariates. The final model included $\log (\mathrm{NMR})$ (cubic spline), log(LBW rate) (cubic spline), log(GNI) (cubic spline), type of data source, definition of stillbirth used, and region as the main effects variables for prediction purposes.

Uncertainty

Uncertainty estimates were derived using the bootstrap approach.

\section{Intrapartum stillbirth rate}

Inputs

Vital registration or national stillbirth registries (15 countries) and studies identified through systematic searches (79 populations from 50 countries) were included (webappendix pp 1-4).

\section{Modelling}

Various strategies to fit a regression model to predict national intrapartum stillbirth rates were studied by use of a range of potential covariates as predictors of intrapartum stillbirth, including NMR, percentage low birthweight, type of data source, definition of stillbirth used, GNI, residence (urban vs rural), region, percentage of skilled attendance, and percentage of caesarean section rate. In view of the data limitations, no satisfactory model was identified, and the median percentage of intrapartum stillbirths for every country or, when not available, every region were applied.

\section{Uncertainty}

Uncertainty estimates for the proportion of stillbirths that are intrapartum were derived by use of regional IQR for regions with more than five input datapoints. For regions with five datapoints or fewer, the upper and lower datapoints were used. We simulated uncertainty estimates for intrapartum stillbirth rates by use of 1000 independent random draws of the uncertainty around the total stillbirth estimates and the uncertainty estimated for the proportion of total stillbirths that were intrapartum.

Sensitivity analysis

Restricting the analysis to studies that reported stillbirths of birthweight of $1000 \mathrm{~g}$ or more or at least 28 weeks' gestation reduced the number of data inputs from 94 to 53 . This restriction led to little difference in regional medians for developed regions ( $11.7 \%$ vs $13.7 \%$ ), east Asia and Eurasia (18.5\% vs $20.0 \%$ ), south Asia and Oceania ( $25.2 \%$ vs 30.9\%), and sub-Saharan Africa ( $47.6 \%$ vs 46.5\%). Larger differences were seen for Latin America and south Asia, possibly partly accounted for by a reduction in the number of input datapoints. For north Africa and west Asia use of data only for stillbirths of birthweight of $1000 \mathrm{~g}$ or more or at least 28 weeks' gestation would have resulted in no identified data sources (webappendix p 4).

\section{Limitations}

Few population-based data reporting intrapartum stillbirths were identified, particularly for low-income countries and with use of the correct definitions. 34 studies were from health facilities in populations with low levels of facility birth, and these data might be biased.

$\mathrm{NMR}=$ neonatal mortality rate. $\mathrm{LBW}=$ low birthweight rate. $\mathrm{GNI}=$ gross national income. measurement focus is on fetal deaths in the last two trimesters of pregnancy and is defined by a birthweight of $500 \mathrm{~g}$ or more; if birthweight is unknown, by gestational age of 22 completed weeks or more; or, if both these criteria are unknown, by crown-heel length of $25 \mathrm{~cm}$ or more (figure 1). If gestational age ( $\geq 22$ weeks) is used rather than birthweight ( $\geq 500 \mathrm{~g}$ ), the stillbirth rate is higher; for example, by about $15 \%$ in Norway. ${ }^{25}$ However, 60 million home births are usually not weighed, even if liveborn; and stillborn babies are often unweighed and rarely measured in hospitals. Hence, in many low-income settings, gestational age is the most widely used criterion, often based on the last menstrual period.

For international comparability, WHO recommends reporting of late fetal deaths (third-trimester stillbirths at $\geq 1000 \mathrm{~g}$ birthweight, $\geq 28$ completed weeks of gestation, $\geq 35 \mathrm{~cm}$ body length). However, countries are also recommended to record outcomes at thresholds lower than 28 weeks to increase reporting of stillbirths after the 28-week cutoff.

The gestation threshold of 28 weeks or longer (thirdtrimester stillbirth) has public health relevance. In countries in which $98 \%$ of neonatal deaths occur, neonatal intensive care is not widely available, ${ }^{7}$ and few births before 28 weeks of gestation survive. ${ }^{26}$ After 32 weeks of gestation, most newborn babies survive with basic care, especially with increasing success with kangaroo mother care. ${ }^{27}$ Additionally, in countries with intensive care, neonatal viability has increased substantially at younger gestational ages over the past two decades. Although few babies born alive at 22 weeks survive, ${ }^{28,29}$ most liveborn babies in high-income countries survive by 25 weeks. ${ }^{30}$ The Nuffield Council on Bioethics recommends that before 22 weeks of gestation, resuscitation should not be attempted, even if a baby is born with signs of life. ${ }^{31}$ This shift in neonatal survival 
has reduced the gestational age cutoff for registering stillbirths in most high-income and some middle-income countries. Thresholds vary from 18 to 28 weeks, ${ }^{32,33}$ and such inconsistency has a large effect on the number of stillbirths reported; for example, moving from a 28 -week to a 22 -week threshold can lead to a $40 \%$ increase in numbers of stillbirths. ${ }^{15,34}$

In this Series, we do not refer to fetal deaths, but instead use the colloquial term stillbirth, which is used by both parents and by professionals, and implies a viable baby born dead. We use the term stillbirth to include all fetal deaths at birthweight of at least $500 \mathrm{~g}$ or at 22 weeks of gestation or later. However, when stillbirth rates are reported in this paper, we use the third-trimester stillbirth definition recommended for international comparison $(\geq 1000 \mathrm{~g}$ birthweight or $\geq 28$ weeks of gestation; figure 1 ).

\section{Counting stillbirths}

\section{Where do the numbers come from?}

In 1983, WHO published a worldwide estimate of 8 million perinatal deaths, ${ }^{35}$ and in 1996 WHO released perinatal mortality estimates with a rate of 58 per 1000 total births in developing countries and a stillbirth rate of 32 per 1000 total births, suggesting 4.3 million stillbirths worldwide. ${ }^{36}$ Although a literature review of stillbirth rates was published in $2006,{ }^{37}$ up to that point, no country-specific rates or numbers of stillbirths had been recorded, impeding visibility and action.

In 2006, two sets of estimates of third-trimester stillbirth rates for 2000 were published. ${ }^{16,17}$ One was developed through a collaborative effort between the Saving Newborn Lives/Save the Children and the Initiative for Maternal Mortality Programme Assessment (IMMPACT) at the University of Aberdeen, UK. ${ }^{16}$ The second was developed by the Making Pregnancy Safer Department of WHO. ${ }^{17}$ These two estimates gave almost the same worldwide totals-3.3 million $^{17}$ and $3 \cdot 2$ million (uncertainty range $2 \cdot 5$ million to $4 \cdot 1$ million $^{16}$ ). However, there were major differences for some individual countries..$^{16,17,38}$

Researchers from several teams, including the Child Health Epidemiology Reference Group (CHERG), Saving Newborn Lives, the Global Alliance to Prevent Prematurity and Stillbirth (GAPPS), and WHO, worked together to identify more data, include more recent data from low-income settings, and refine the modelling methods to comply as closely as possible with published recommendations on systematic and transparent worldwide estimates. The model was then applied to estimate trends. The details of the inputs and methods are published elsewhere, ${ }^{38}$ and the panel provides a brief summary.

\section{Where do stillbirths occur?}

\section{Regional and national variation}

In 2008, a worldwide total of 2.65 million (uncertainty range 2.08 million to 3.79 million) stillbirths was estimated..$^{38} 98 \%$ of these third-trimester stillbirths were in low-income and middle-income countries, and more than three-quarters were in south Asia and sub-Saharan Africa (table 1).

Variation in stillbirth rates among countries is substantial. In high-income countries, the third-trimester stillbirth rate is less than four per 1000 total births (uncertainty range 35500-38000), a quarter of the worldwide average and a ninth of the average in south Asia and sub-Saharan Africa. ${ }^{38}$ Finland has the lowest reported rate at 2.0 per 1000 total births, and Nigeria (41.9 per 1000 total births) and Pakistan (46.1 per 1000 total births) have the highest estimated rates. Even within the same region there is great variation in stillbirth rates. For example, in sub-Saharan African countries, Mauritius and the Seychelles have estimated thirdtrimester stillbirth rates of ten or less per 1000 total births compared with rates of more than 30 in Côte D'Ivoire, Democratic Republic of the Congo, Djibouti, Senegal, Nigeria, Somalia, and Sierra Leone (figure 2) ${ }^{38}$ However, there is wide uncertainly in national estimates, especially those with poor national input data. For example, the estimate for Afghanistan is 29.4 per 1000 total births, giving 38000 stillbirths with a range from 24000 to 72000 (webappendix pp 5-12).

Ten populous countries (India, Pakistan, Nigeria, China, Bangladesh, Democratic Republic of the Congo, Ethiopia, Indonesia, Tanzania, and Afghanistan) account for two-thirds of all third-trimester stillbirths (table 2). The five highest of these countries account for more than half of all stillbirths and maternal and neonatal deaths and are crucial for progress towards worldwide goals. Of note, during the past decade, China has dropped from the second to fourth highest burden of stillbirths because of a rapid reduction in stillbirth rate and a reduced total fertility rate. Nigeria has moved up to the second highest as the national stillbirth rate and total

\begin{tabular}{|c|c|c|c|c|c|}
\hline & \multirow{2}{*}{$\begin{array}{l}\text { Estimated } \\
\text { stillbirth } \\
\text { rate per } \\
1000 \text { total } \\
\text { births }\end{array}$} & \multirow{2}{*}{$\begin{array}{l}\text { Number } \\
\text { of } \\
\text { stillbirths }\end{array}$} & \multicolumn{2}{|c|}{ Uncertainty range } & \multirow{2}{*}{$\begin{array}{l}\text { Estimated } \\
\text { intrapartum } \\
\text { stillbirths (\%) }\end{array}$} \\
\hline & & & Low & High & \\
\hline High-income countries & $3 \cdot 1$ & 36300 & 35500 & 38200 & $13 \cdot 7$ \\
\hline East Asia & $9 \cdot 0$ & 171400 & 116200 & 278600 & $20 \cdot 0$ \\
\hline Latin America and the Caribbean & $9 \cdot 4$ & 101800 & 83300 & 125400 & $23 \cdot 1$ \\
\hline Eurasia & $9 \cdot 0$ & 33500 & 31300 & 42700 & $20 \cdot 0$ \\
\hline Southeast Asia and Oceania & $14 \cdot 2$ & 164300 & 130400 & 235700 & $30 \cdot 9$ \\
\hline $\begin{array}{l}\text { North Africa and west Asia } \\
\text { (Middle East) }\end{array}$ & $12 \cdot 9$ & 112300 & 88900 & 165100 & $16 \cdot 4$ \\
\hline Sub-Saharan Africa & $29 \cdot 0$ & 943900 & 701800 & 1388800 & $46 \cdot 5$ \\
\hline South Asia & $26 \cdot 7$ & 1083000 & 835900 & 1671000 & $56 \cdot 6$ \\
\hline Worldwide & $19 \cdot 1$ & 2646800 & 2077010 & 3790420 & $45 \cdot 0$ \\
\hline
\end{tabular}




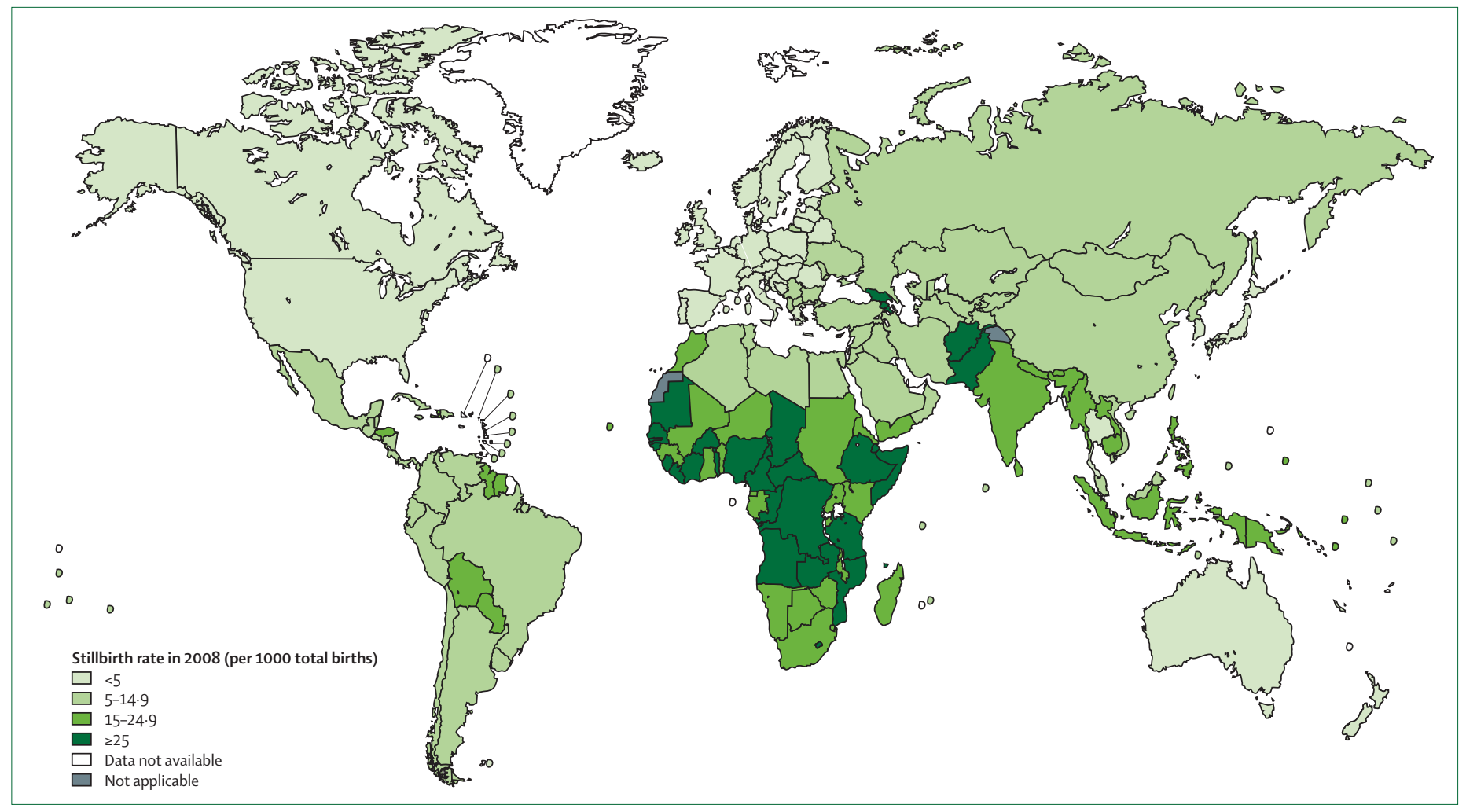

Figure 2: Country variation in third-trimester stillbirth rates in 2008

\begin{tabular}{|llll}
\hline & $\begin{array}{l}\text { Rank for number of } \\
\text { stillbirths }\end{array}$ & $\begin{array}{l}\text { Rank for number of } \\
\text { maternal deaths }\end{array}$ & $\begin{array}{l}\text { Rank for number of } \\
\text { neonatal deaths }\end{array}$ \\
\hline India & 1 & 1 & 1 \\
Nigeria & 2 & 2 & 2 \\
Pakistan & 3 & 7 & 3 \\
\hline China & 4 & 12 & 4 \\
Bangladesh & 5 & 8 & 7 \\
Democratic Republic of the Congo & 6 & 3 & 5 \\
Ethiopia & 7 & 5 & 6 \\
\hline Indonesia & 8 & 9 & 8 \\
\hline Tanzania & 9 & 6 & 10 \\
\hline Afghanistan & 10 & 4 & 9 \\
Total & 1.8 million stillbirths; & 221000 maternal & $2 \cdot 4$ million neonatal \\
& $66 \%$ of worldwide & death; $62 \%$ of & deaths; $67 \%$ of \\
& total & worldwide total & worldwide total
\end{tabular}

Table adapted from Lawn and colleagues..$^{39}$ Data for stillbirths from Cousens and colleagues, ${ }^{38}$ for neonatal deaths from Black and colleagues, ${ }^{40}$ and for maternal health from UNICEF. ${ }^{41}$

Table 2: Top ten countries for absolute number of stillbirths, maternal deaths, and neonatal deaths in 2008

fertility rate remain high, emphasising the importance of family planning in reducing deaths for mothers, newborn babies, and stillbirths.

\section{Subnational variation in rates}

There are also major differences within countries. In India, there are an estimated 613500 third-trimester stillbirths every year, with a rate of 22 per 1000 total births (uncertainty range 17-36), but variation between states is large, with rates of less than 20 per 1000 total births in Kerala ${ }^{42}$ and rates of 66 per 1000 total births or more in central India. ${ }^{43}$ Similarly, the rates in rural northern communities in Nigeria are higher ${ }^{44}$ than those for urban teaching hospitals in southern Nigeria. ${ }^{45}$ In China, the stillbirth rate for rural, ethnic minority groups $^{46}$ is reported to be three-times higher than that for urban populations. ${ }^{47}$

In high-income countries and in Latin America, most stillbirths are in urban populations, indicating the predominance of urban living in these countries. In south Asia and sub-Saharan Africa, the predominantly rural populations mean that more than two-thirds of all stillbirths in these regions are rural (771000 in south Asia, 681000 in sub-Saharan Africa). Worldwide, two-thirds of all stillbirths occur in rural families (figure 3).

Furthermore, these differences are consistent with disparities in skilled attendance at birth, which is at least $50 \%$ lower for women in rural areas in Africa and south Asia than that for women in urban settings. ${ }^{48}$ The gap between urban and rural settings for caesarean section is even greater. South Asia has an urban caesarean section rate of $14 \%$, with $5 \%$ for rural settings. Africa has low caesarean section rates at $5 \%$ for urban and only $1 \%$ for rural settings. ${ }^{49}$ Burkina Faso, Chad, Ethiopia, and Niger all have rural caesarean section rates of almost zero. ${ }^{48}$ 


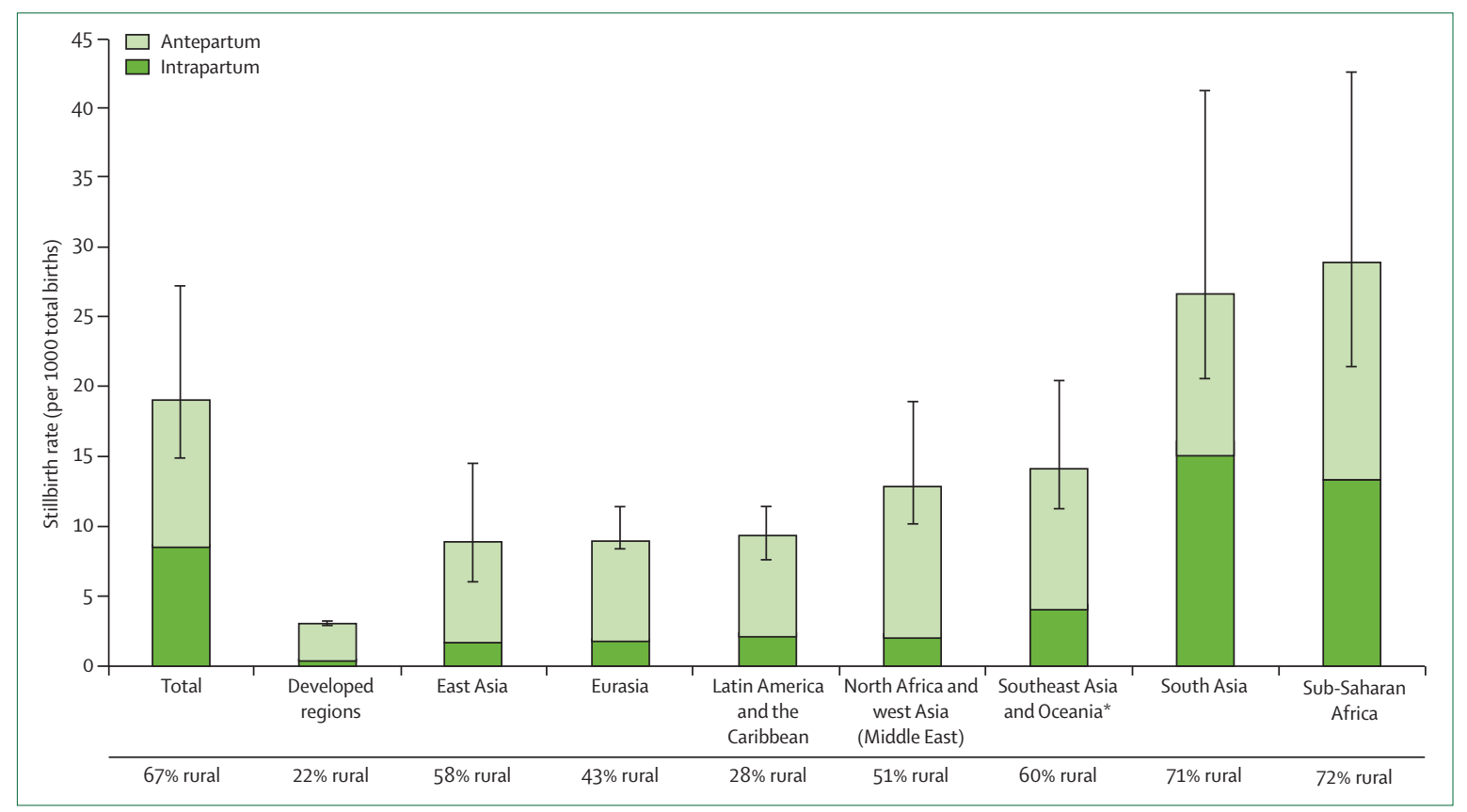

Figure 3: Regional variation in stillbirth rates and the proportion of intrapartum stillbirths

Error bars indicate uncertainty range for the stillbirth rate estimate. Data sources from the panel and webappendix pp 5-12.

\section{Association with maternal and neonatal mortality and health systems}

When countries are categorised by stillbirth rate $(<5,5-14 \cdot 9,15-24 \cdot 9$, and $\geq 25$ per 1000 total births $)$, there are clear correlations with maternal and neonatal mortality, as well as with health-system indicators (table 3, webappendix pp 13-14). In 48 high-income countries, stillbirth rates are less than five per 1000 total births, accounting for less than $2 \%$ of stillbirths worldwide. In these countries, the median number of nurses and midwives per 1000 population is $7 \cdot 7$, all births are with a skilled attendant, and neonatal and maternal deaths are also rare events. By contrast, 28 low-income countries with stillbirth rates of at least 25 per 1000 total births account for $43 \%$ of stillbirths worldwide. In these countries, half of births occur at home without skilled care and the median number of nurses and midwives per 1000 population is $0 \cdot 5$, compared with a minimum of 2.0 recommended by WHO. In countries with the heaviest health burdens, the health systems are struggling and the data are weak for setting priorities, improving outcomes, and tracking progress. The local health systems context is crucial, especially for planning maternal, neonatal, and stillbirth programmes. ${ }^{21}$

\section{When do stillbirths occur?}

A practical grouping of stillbirths is by time of death: antepartum (before the onset of labour) or intrapartum (during labour and birth; figure 1). The worldwide intrapartum stillbirth estimates we provide here are based on similar methods to previous country estimates, ${ }^{50}$ with use of median regional intrapartum stillbirth percentages. The panel details the inputs (94 datasets, webappendix pp 1-4), methods, and limitations of these estimates. A sensitivity analysis of 53 datasets with a stricter stillbirth rate definition ( $\geq 1000$ g birthweight or $\geq 28$ weeks of gestation) made little difference to most regional estimates, but included no datapoints for north Africa and west Asia, and reduced the number of datapoints for Latin America and south Asia. The data available do not support more complex models accounting for more than the region. More data are urgently needed to track this important outcome, which is a sensitive measure of care at birth.

Labour and birth are the time of highest risk, with an estimated 1.19 million intrapartum stillbirths (uncertainty range 0.82 million to 1.97 million), equivalent to $45 \%$ of the yearly worldwide third-trimester stillbirths and slightly higher than the last worldwide estimate for 2000 of 1.02 million (uncertainty range 0.66 million to 1.48 million), ${ }^{47}$ and also suggesting greater regional variation in the proportion of stillbirths estimated to be intrapartum than in the previous estimates (panel, webappendix p 4). In high-income countries, intrapartum stillbirth rates are typically less than 0.5 per 1000 total births, or about $14 \%$ of thirdtrimester stillbirths, compared with rates of 12 per 1000 total births or higher ( $>50 \%$ of stillbirths) in many countries in south Asia and sub-Saharan Africa (table 1, figure 3). Most babies who die during labour are term babies who should survive if born alive and their deaths are often associated with suboptimal care..$^{50,51}$ 


\begin{tabular}{|c|c|c|c|c|}
\hline & $\begin{array}{l}<5 \text { per } \\
1000 \text { total births }\end{array}$ & $\begin{array}{l}5-14.9 \text { per } \\
1000 \text { total births }\end{array}$ & $\begin{array}{l}15-24.9 \text { per } \\
1000 \text { total births }\end{array}$ & $\begin{array}{l}\geq 25 \text { per } \\
1000 \text { total births* }\end{array}$ \\
\hline Numbers of stillbirths in countries with the stillbirth rate & 45000 & 470000 & 1010000 & 1120000 \\
\hline Number of countries with the stillbirth rate & 48 & 74 & 43 & 28 \\
\hline Intrapartum stillbirth rate (weighted per 1000 total births) & 0.5 & $2 \cdot 4$ & $11 \cdot 0$ & $17 \cdot 6$ \\
\hline Proportion of intrapartum stillbirths & $16 \cdot 4 \%$ & $23 \cdot 4 \%$ & $50 \cdot 4 \%$ & $50 \cdot 3 \%$ \\
\hline Median gross national income per person & $\begin{array}{l}\text { US\$29540 } \\
\text { (high income) }\end{array}$ & $\begin{array}{l}\text { US\$3710 } \\
\text { (middle income) }\end{array}$ & $\begin{array}{l}\text { US } \$ 910 \\
\text { (low income and } \\
\text { middle income) }\end{array}$ & $\begin{array}{l}\text { US\$450 } \\
\text { (low income) }\end{array}$ \\
\hline Median maternal mortality ratio (maternal deaths per 100000 livebirths) & $7 \cdot 7$ & $38 \cdot 1$ & $257 \cdot 3$ & $576 \cdot 3$ \\
\hline Median neonatal mortality rate (neonatal deaths per 1000 livebirths) & $2 \cdot 7$ & $10 \cdot 1$ & $25 \cdot 5$ & 38.9 \\
\hline Median percentage of births with a skilled birth attendant & $100 \%$ & $98 \%$ & $65 \%$ & $50 \%$ \\
\hline Median percentage of births by caesarean section & $20 \cdot 0 \%$ & $15 \cdot 3 \%$ & $4.8 \%$ & $3 \cdot 2 \%$ \\
\hline Median nurse or midwife density per 1000 population & $7 \cdot 6$ & $3 \cdot 3$ & 1.0 & 0.5 \\
\hline
\end{tabular}

For more on Countdown to 2015 profiles see $h t t p: / / w w w$. countdown2015mnch.org
Birth, and the first few hours and days after birth, are also times of high risk of death for women and newborn babies. This period is the key time for programmatic action to reduce third-trimester stillbirths, materna ${ }^{52}$ and neonatal deaths, ${ }^{7}$ and maternal morbidity (such as obstetric fistula), neonatal morbidity, and lifelong disability subsequent to neonatal complications.

\section{Why do stillbirths occur?}

To reduce the numbers of stillbirths, basic information on causation is crucial. ${ }^{8}$ National neonatal cause-of-death estimates have been published, ${ }^{7,53}$ are regularly updated through the $\mathrm{UN}^{40}$ and disseminated by Countdown to 2015 national data profiles. This process has helped to focus on the three major causes of neonatal death (infections, intrapartum-related causes, and preterm birth complications). ${ }^{39}$ National estimates of stillbirth causes do not exist. Two fundamental challenges must be addressed-consensus on causal categories, linked with maternal conditions, is needed and the absence of comparable population-based data consistent with these categories needs to be resolved.

More than 35 stillbirth classification systems have been published over the past 50 years, with more than 15 of these in the past 15 years. ${ }^{25,54,55}$ Approaches vary, with some focusing on fetal causes (Wigglesworth), others on maternal causes (Aberdeen) or placental pathology, or a combination of both. ${ }^{54,55}$ The most recent classification systems have been devised for high-income countries and have complex categories requiring placental examination, advanced diagnostics, and post-mortem services. Some allow more than one cause per death, which is useful for programmes but not compatible with ICD rules. The International Stillbirth Alliance has examined the usefulness of several classification systems to identify the most prevalent causes in high-income settings. ${ }^{56}$ The system introduced by Wigglesworth did worst, yet is the most widely used in low-income and middle-income countries because this system is simple to use and has been used for decades. ${ }^{56}$ Even in Malaysia and South Africa, the application of new classifications were impeded by little placental or cord information, few other investigations such as karyotyping, placental histology, and thrombophilia screening, a total absence of post-mortem data, and reliance on maternal history. ${ }^{56}$ Another problem, even in high-income countries, is detection of fetal growth restriction because of placental failure as a frequent antecedent of stillbirth. ${ }^{14,57,58}$ By use of a complex classification that includes fetal growth restriction and rigorous investigation, the unidentified cause group can be reduced to less than $30 \%{ }^{56}$ or even less than $20 \%$. . $^{57,59}$

The poor comparability between multiple classification systems is the most substantial barrier to any meta-analysis and estimates for stillbirth causation. Hence, agreement is needed to map increasingly complex cause-of-death classifications used in high-income settings onto simple programmatic categories that are feasible and relevant in low-income settings.

The simplest level is based on time of stillbirth (antepartum and intrapartum). This information is feasible in low-income settings, including home births and is programmatically relevant. To prevent antepartum stillbirths, improved maternal health and care during pregnancy is needed, whereas better obstetric care is needed to avoid intrapartum stillbirths. Every antepartum and intrapartum stillbirth should be allocated to a restricted choice of clinically identifiable, mutually exclusive categories that can be differentiated clinically or with a verbal autopsy approach (eg, major congenital abnormalities, chorioamnionitis). More detailed causes of death can be distinguished with laboratory investigation and examination of the placenta, and coded with complex classification systems and ICD codes.

Given the paucity of national estimates for causes of stillbirth, we used typical datasets to investigate variation with stillbirth rates $(<5,5-14 \cdot 9,15-24 \cdot 9$, and $\geq 25$ per 


\begin{tabular}{|c|c|c|c|}
\hline & $\begin{array}{l}\text { SBR }<5 \text { per } 1000 \text { total births } \\
\text { (six high-income } \\
\text { country datasets*) }\end{array}$ & $\begin{array}{l}\text { SBR } 15-24 \text { per } 1000 \text { total } \\
\text { births (South Africa } \\
\text { national data) }\end{array}$ & $\begin{array}{l}S B R \geq 25 \text { per } 1000 \text { total } \\
\text { births (Bangladesh } \\
\text { rural hospital data) }\end{array}$ \\
\hline \multicolumn{4}{|l|}{ Dataset details } \\
\hline SBR of input data & $2-4$ & 19 & 39 \\
\hline Year of input data & 2008-09 & 2008-09 & 2007-09 \\
\hline Antepartum stillbirths (\%) & $316(91 \%)$ & $11085(61 \%)$ & $138(34 \%)$ \\
\hline \multicolumn{4}{|l|}{ Stillbirth category } \\
\hline Congenital & $11 \%$ & $2 \%$ & $1 \%$ \\
\hline Infection & $6 \%$ & $6 \%$ & $5 \%$ \\
\hline Fetal growth restriction or placental insufficiency & $32 \%$ & $3 \%$ & $28 \%$ \\
\hline Other specific fetal condition & $8 \%$ & $1 \%$ & $13 \%$ \\
\hline No stillbirth condition identified (maternal event identified) & $43 \%$ & $88 \%(18 \%)$ & $54 \%(17 \%)$ \\
\hline \multicolumn{4}{|l|}{ Associated maternal condition } \\
\hline Abnormal labour or uterine rupture & $0 \%$ & $0 \%$ & $9 \%$ \\
\hline Maternal hypertension & $11 \%$ & $20 \%$ & $9 \%$ \\
\hline Maternal infection (eg, syphilis) & $0 \%$ & $4 \%$ & $1 \%$ \\
\hline Chorioamnionitis & $5 \%$ & $2 \%$ & $3 \%$ \\
\hline Maternal diabetes & $8 \%$ & $2 \%$ & $0 \%$ \\
\hline Antepartum haemorrhage (abruptio placenta or placenta praevia) & $15 \%$ & $6 \%$ & $9 \%$ \\
\hline Maternal pre-existing condition (eg, cardiac) & $0 \%$ & $2 \%$ & $2 \%$ \\
\hline Spontaneous preterm labour & .. & .. & $1 \%$ \\
\hline Other maternal specific & $9 \%$ & $1 \%$ & $1 \%$ \\
\hline No maternal condition identified & $62 \%$ & $62 \%$ & $65 \%$ \\
\hline \multicolumn{4}{|c|}{$\begin{array}{l}\text { No usable data were identified in the SBR group of 5-14.9 per } 1000 \text { total births, mainly because of no consistent coding for maternal conditions. Variation according to } \\
\text { increasing levels of SBR from less than five per } 1000 \text { total births to } 25 \text { per } 1000 \text { total births or more. This table does not present all conditions, because only one fetal and/or } \\
\text { one maternal condition were registered as per recommendations from the International Classification of Diseases. If more conditions are identified by use of a complex } \\
\text { system, and more investigations are available, then fewer than } 20 \% \text { of stillbirths have an unidentified condition. *SBR < } 5 \text { per } 1000 \text { total births includes data from Australia } \\
\text { (Queensland Maternal Perinatal Quality Council), Canada (Alberta Perinatal Health Program), the Netherlands (Foundation Perinatal Audit), Norway (Norwegian Birth } \\
\text { Registry), the UK (Centre for Maternal and Child Enquiries), and the USA (Centers for Disease Control and Prevention). SBR=stillbirth rate. ."=no data. }\end{array}$} \\
\hline
\end{tabular}

1000 total births). Datasets were included if they had more than 200 stillbirths, a reference year of 2006 or later, and data that could be analysed according to the agreed categories and definitions (table 4 and table 5).

Despite data limitations, variations are apparent. The proportion of intrapartum stillbirths increases as the stillbirth rate increases from less than $10 \%$ to more than $60 \%$ (figure 3, table 4 , and table 5). Some of the other variations might be artifacts related to measurement gaps. For example, the proportion of intrapartum stillbirths attributed to infection is apparently higher in high-income and middle-income settings than that in low-income countries (table 5), which might be indicative of detection bias and little laboratory investigation in lowincome countries. Syphilis is unlikely to be identified in the absence of serological testing. There are no obvious differences in proportion of stillbirths attributed to congenital abnormalities, which might indicate both a real reduction in numbers in high-income countries because of termination and better care or could be attributable to missed cases in low-income settings, where only very obvious external abnormalities are noted. ${ }^{60-63}$

Among antepartum stillbirths, the largest category is the unidentified condition (table 4). Analyses of classification systems have indicated that the identified proportion of stillbirths varies according to the classification system used $^{56,64,65}$ and with the level of laboratory investigation and perinatal autopsy; thus, in the context of high stillbirth rates, that more stillbirths have an unidentified cause is unsurprising. ${ }^{66-68}$ Fetal growth restriction is more often detected in high-income countries because ultrasound is a more accurate method than is tape measure (table 4). Of antepartum stillbirths with an unidentified cause, about a third in South Africa and Bangladesh had a maternal event such as antepartum haemorrhage, easily identifiable through history, indicating the value of also collecting data on the maternal condition.

\section{The importance of maternal conditions for stillbirths and neonatal deaths}

Pregnancy outcomes for mothers and babies are closely linked, yet few datasets present information on all the relevant outcomes. The ICD recommends that every stillbirth and neonatal death should be given a code for a direct cause and a separate code for maternal cause, enabling better assessment of attributable risk and programmatic implications. For example, fetal growth restriction is common and is possibly linked with 


\begin{tabular}{|c|c|c|c|}
\hline & $\begin{array}{l}\text { SBR }<5 \text { per } 1000 \text { total births } \\
\text { (six high-income } \\
\text { country datasets) }\end{array}$ & $\begin{array}{l}\text { SBR } 15-24 \text { per } 1000 \text { total } \\
\text { births (South Africa } \\
\text { national data) }\end{array}$ & $\begin{array}{l}\text { SBR } \geq 25 \text { per } 1000 \text { total } \\
\text { births (Bangladesh } \\
\text { rural hospital data) }\end{array}$ \\
\hline \multicolumn{4}{|l|}{ Database details } \\
\hline SBR of input data & $2-4$ & 19 & 39 \\
\hline Year of input data & 2008-09 & 2008-09 & 2007-09 \\
\hline Intrapartum stillbirths (\%) & $30(9 \%)$ & $7083(39 \%)$ & $264(66 \%)$ \\
\hline \multicolumn{4}{|l|}{ Stillbirth category } \\
\hline Congenital & $10 \%$ & $4 \%$ & $4 \%$ \\
\hline Infection & $17 \%$ & $5 \%$ & $2 \%$ \\
\hline Fetal growth restriction or placental insufficiency & $26 \%$ & $1 \%$ & $6 \%$ \\
\hline Other specific fetal condition & $4 \%$ & $1 \%$ & $17 \%$ \\
\hline No stillbirth condition identified (maternal event identified) & $43 \%$ & $88 \%(59 \%)$ & $71 \%(58 \%)$ \\
\hline \multicolumn{4}{|l|}{ Associated maternal condition } \\
\hline Abnormal labour or uterine rupture & $10 \%$ & $29 \%$ & $44 \%$ \\
\hline Maternal hypertension & $0 \%$ & $19 \%$ & $14 \%$ \\
\hline Maternal infection (eg, syphilis) & $0 \%$ & $3 \%$ & $0 \%$ \\
\hline Chorioamnionitis & $17 \%$ & $2 \%$ & $2 \%$ \\
\hline Maternal diabetes & $0 \%$ & $1 \%$ & $0 \%$ \\
\hline Antepartum haemorrhage (abruptio placenta or placenta praevia) & $10 \%$ & $17 \%$ & $15 \%$ \\
\hline Maternal pre-existing disorder (eg, cardiac) & $0 \%$ & $1 \%$ & $2 \%$ \\
\hline Spontaneous preterm labour & $7 \%$ & $5 \%$ & $0 \%$ \\
\hline Other maternal specific condition & $0 \%$ & $1 \%$ & $4 \%$ \\
\hline No maternal condition identified & $56 \%$ & $22 \%$ & $19 \%$ \\
\hline \multicolumn{4}{|c|}{$\begin{array}{l}\text { No usable data were identified in the SBR group of 5-14.9 per } 1000 \text { total births, mainly because of no consistent coding for maternal conditions. Variation according to } \\
\text { increasing levels of SBR from less than five per } 1000 \text { total births to } 25 \text { per } 1000 \text { total births or more. This table does not present all conditions, because only one fetal and/or } \\
\text { one maternal condition were registered as per recommendations from the International Classification of Diseases. If more conditions are identified by use of a complex } \\
\text { system, and more investigations are available, then fewer than } 20 \% \text { of stillbirths have an unidentified condition. *SBR }<5 \text { per } 1000 \text { total births includes data from Australia } \\
\text { (Queensland Maternal Perinatal Quality Council), Canada (Alberta Perinatal Health Program), the Netherlands (Foundation Perinatal Audit), Norway (Norwegian Birth } \\
\text { Registry), the UK (Centre for Maternal and Child Enquiries), and the USA (Centers for Disease Control and Prevention). SBR=stillbirth rate. }\end{array}$} \\
\hline
\end{tabular}

maternal hypertension, yet the information is lost if only fetal growth restriction is coded. In high-income settings, coding and analysis of all the associated conditions is possible. In low-income settings, although recording of at least one stillbirth or neonatal cause and one associated maternal condition is feasible, as recommended by the ICD, this action is poorly implemented. There are many maternal conditions potentially associated with stillbirth. Some, such as hypertension and diabetes, are important in all countries, whereas others are context specific; for example, high prevalence of syphilis, malaria, or HIV infection ${ }^{69,70}$ or maternal undernutrition in low-income countries and obesity or smoking in middle-income and high-income countries. ${ }^{14}$ Other risk factors such as female literacy and socioeconomic status are also important and are discussed in other papers in this Series. ${ }^{14,20,21}$

To assess the association between maternal conditions and stillbirths and neonatal deaths, we analysed South African perinatal audit data for 2008-09, which covers more than half of the births in South Africa and includes almost 20000 stillbirths ${ }^{71}$ (figure 4 )..$^{72} 80 \%$ of early neonatal deaths, $75 \%$ of intrapartum stillbirths, and about half of antepartum stillbirths were associated with an identified maternal condition, and the most common conditions were those that also have high morbidity in women. For example, hypertensive disease of pregnancy was associated with about $20 \%$ of intrapartum and $10 \%$ of antepartum stillbirths and $6 \%$ of neonatal deaths. Maternal conditions most often associated with perinatal death in South Africa are, in order, obstructed labour, hypertensive disease of pregnancy, preterm labour, antepartum haemorrhage, and maternal infections and chorioamnionitis.

Analysis with the associated maternal condition is valuable. In the South African national dataset, most antepartum stillbirths had an unidentified cause but, of these, $20 \%$ had mothers with hypertension and another $1 \%$ had diabetes or other medical disorders (figure 4). Diabetes might be being missed, as the expected prevalence in pregnancy is $5 \%$. More than half of the intrapartum stillbirths without an identified cause were associated with abnormal labour or maternal hypertension. Only 3\% of early neonatal deaths had an unidentified cause.

\section{Trends and predicting progress to 2020}

New estimates of stillbirth trends from 1995 to $2009^{38}$ suggest that the average worldwide yearly rate of reduction of stillbirths has reduced by $1 \cdot 1 \%$, which is lower than the reduction for mortality in children younger than 5 years 


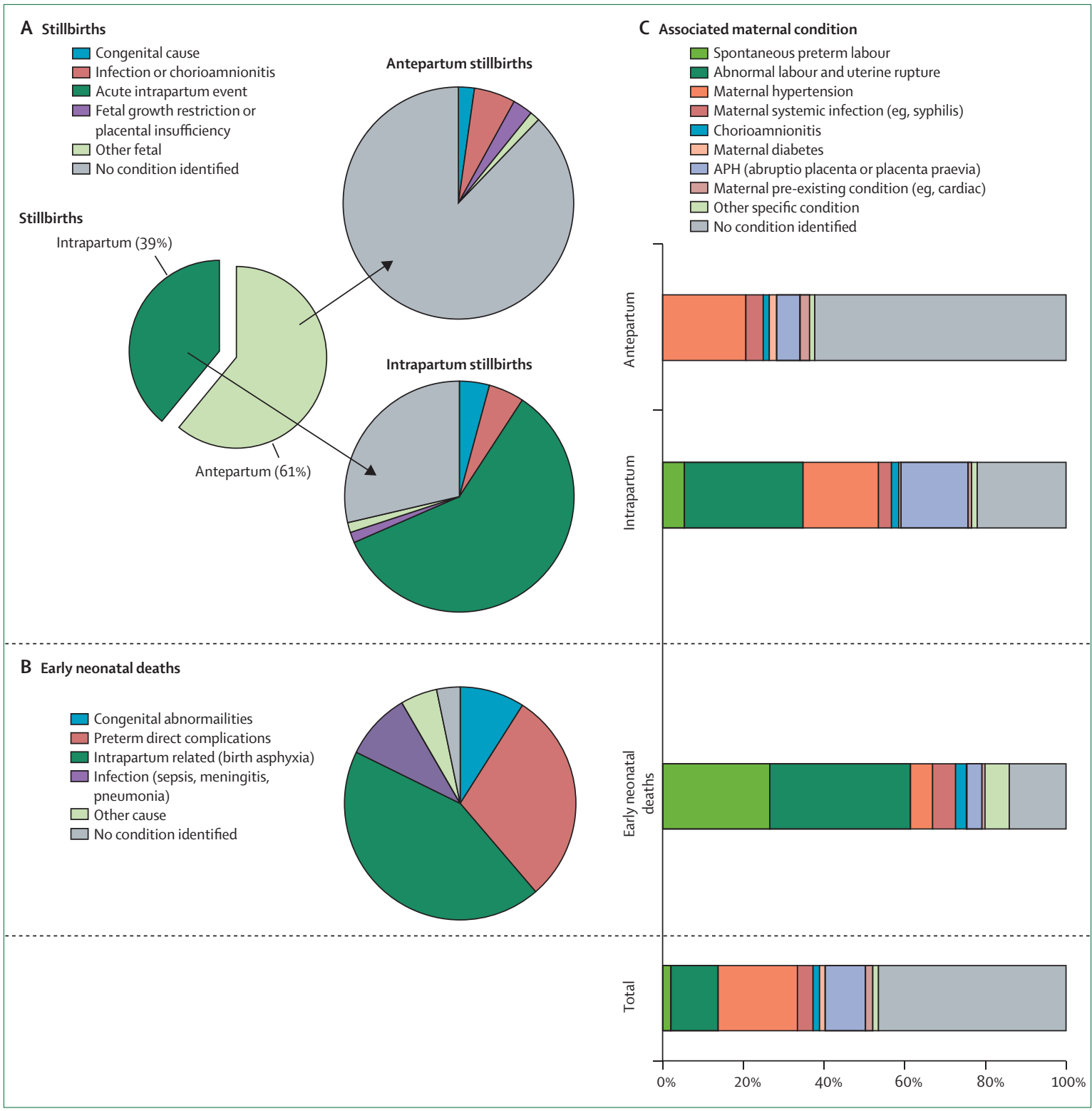

Figure 4: Antepartum stillbirths, intrapartum stillbirths, and early neonatal deaths with fetal (A) or neonatal (B) causes and associated maternal conditions (C) Data based on 19976 stillbirths and 8562 neonatal deaths in South Africa, 2008-09. Data from Medical Research Council Maternal and Infant Health Care Strategies Research Unit. ${ }^{72} \mathrm{APH}=$ antepartum haemorrhage.

$(2 \cdot 3 \%)^{9}$ and is less than that for maternal mortality reduction at $1.3 \%\left(1990-2008^{73}\right), 2 \cdot 5 \% \quad\left(1990-2005^{74}\right)$, or $2 \cdot 1 \%\left(1990-2008^{41}\right)$. The slowest decline is seen in subSaharan Africa and South Asia, with almost no change in sub-Saharan Africa since 2000 (figure 5). This pattern indicates slow progress in neonatal mortality rate reduction for these regions, especially for Africa-notably, neonatal mortality rate was a predictor in the stillbirth rates model. By contrast, in east Asia, a halving of the stillbirth rate has been driven by a large reduction in stillbirths in China. Latin America, Eurasia, and east Asia have made progress in reducing numbers of stillbirths and mortality in children younger than 5 years and neonates.
Assuming that trends from 1995 to 2009 remain constant, the worldwide stillbirth rate in 2020 is projected to be about 16.7 per 1000 total births, with the slowest progress in sub-Saharan Africa. South Asia and sub-Saharan Africa would still have high stillbirth rates ( $\geq 24$ per 1000 total births), with 18 countries in these regions still in the highest stillbirth rate band ( $\geq 25$ per 1000 total births) and a widening gap between these regions and Latin America and southeast Asia (figure 3). If no new efforts are made to prevent stillbirths or to reduce unwanted pregnancies, particularly for lowincome families in rural settings, then we estimate that, by 2020, more than 2 million stillbirths will still occur 


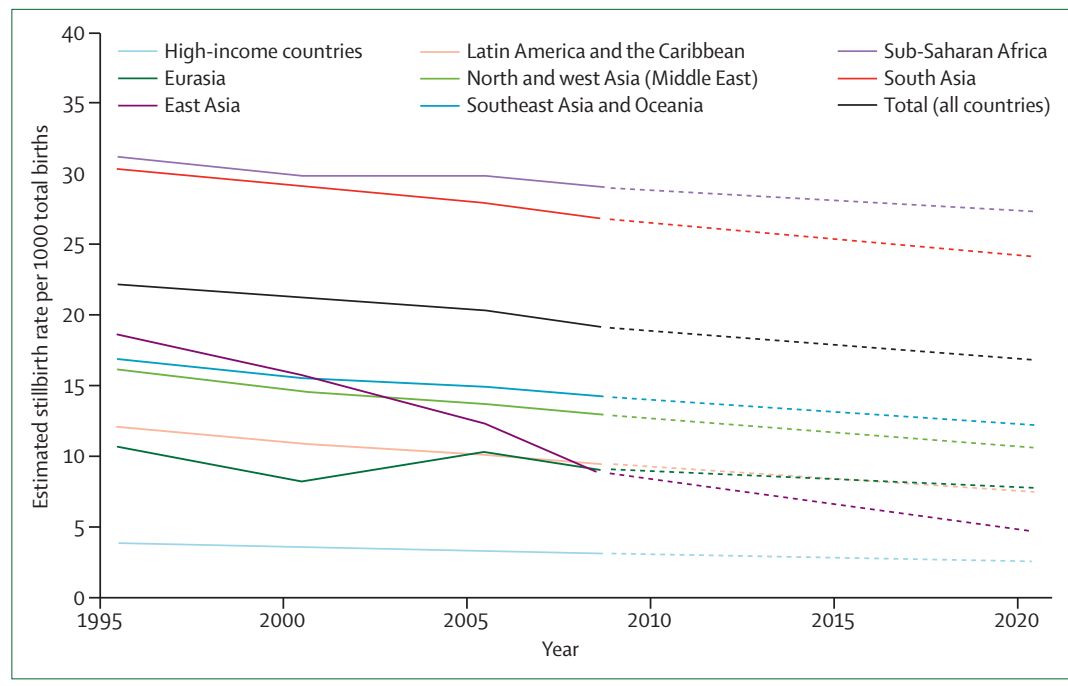

Figure 5: Estimated stillbirth rate trends by region, 1995-2008, with predictions to 2020

Predictions based on average yearly percentage reduction in stillbirth rate from 1995 to 2008. Data sources from the panel. Projections levelled once target stillbirth rate of five per 1000 total births is achieved.

every year, with potentially $90 \%$ in sub-Saharan Africa and south Asia.

Long-term trends in selected high-income countries, from 1750 to 2000 indicate that most of these countries had a stillbirth rate of about 30 per 1000 total births in $1900,{ }^{22}$ which is similar to current stillbirth rates in many low-income countries. High-income countries reported a substantial reduction in stillbirth rates of two-thirds between 1950 and 1975 related to prevention and treatment of infection and improved obstetric care. ${ }^{22}$ This reduction occurred before more complex fetal surveillance and diagnostics and also coincided with major reductions in maternal and neonatal mortality. 60 years later, the poor progress to reduce all three of these pregnancy outcomes in low-income countries is not a knowledge gap but an action gap.

\section{Improving national stillbirth data for action Improving stillbirth rate estimation}

Exercises to estimate worldwide third-trimester stillbirth rates are important for worldwide policy and programme prioritisation, but do not address the urgent need for high-quality, recent data at country level. Although there is no doubt that stillbirths are a large problem, much of our information depends on estimates and focuses on third-trimester stillbirths. Present estimates are likely to be an underestimate, particularly in the highest mortality settings for which the data are sparse. Because $98 \%$ of worldwide third-trimester stillbirths occur in countries without reliable vital registration, reliance on other data sources is inevitable in the immediate future. ${ }^{38}$ For 81 countries, predominantly low-income settings, no nationally representative stillbirth data were available.

The quantity and quality of pregnancy outcome data, including stillbirth data, must be improved (figure 6). ${ }^{38,75}$
Improving civil registration systems, adding specific perinatal death certificates, and expanding the ICD codes for stillbirth during ICD-11 planning are all crucial, especially for middle-income countries. ${ }^{76}$ However, the largest and most rapid increase in data available now would be through inclusion of reliable stillbirth capture in existing household surveys." These surveys, especially the demographic health surveys (DHS) and UNICEF's multiple indicator cluster surveys, provide more than $75 \%$ of worldwide data for neonatal and child deaths. DHS rely on retrospective pregnancy histories over the past 5 years and are unreliable for stillbirth data at present, although some surveys do capture stillbirths more accurately. ${ }^{75}$ Important assessments include the validity, reliability, and interview duration for a pregnancy history compared with livebirth history, and assessing the validity and reliability of a truncated (eg, past 5 years) history versus a complete history. The expanded number of demographic surveillance sites in operation in various low-income countries, particularly the sites covered by the International Network for the Demographic Evaluation of Populations and Their Health in Developing Countries, offer opportunities to study these factors to compare retrospective reporting of pregnancy outcomes against prospective, gold standard data and to assess time taken and cost. ${ }^{75}$

Improving stillbirth causal data for programmatic action Although the analysis presented here is a step forward, it falls far short of systematic national estimates such as those that are available for neonatal cause of death for all countries. ${ }^{53}$ Additionally, improved understanding of maternal conditions associated with stillbirth and neonatal death would provide a firmer foundation for prioritising interventions to benefit the mother, fetus, and neonate.

Two steps are crucial (figure 6). First, we need consensus on a core list of programmatic causes of stillbirth to compare with maternal conditions and that can be distinguished through clinical observations and verbal autopsy. ${ }^{75}$ This consensus will need a wide coalition of partners, including the UN, groups who collect and use data in low-income settings, and those who generate estimates, including academics, plus relevant highincome country groups such as the International Stillbirth Alliance. Second, the quantity and quality of input data, especially from low-income and middleincome settings, must be improved to generate enough data to develop national estimates. ICD-10 codes do not capture important categories for stillbirths. The revision of ICD-11 that is underway provides an important opportunity to improve these codes. Additionally, vital registration data for stillbirths collected by countries should be routinely reported or compiled by the UN, like data for neonatal and child deaths.

In high-mortality settings, verbal autopsy methods have been used to help distinguish fresh stillbirths from macerated ones as a recognised proxy for intrapartum stillbirth. In some studies, this proxy has correlated well 


\begin{tabular}{|c|c|c|c|c|}
\hline & $\begin{array}{r}\text { SBR } \\
\text { (per } 1000 \\
\text { total births) }\end{array}$ & $5-14 \cdot 9$ & $15-24 \cdot 9^{*}$ & $\geq 25^{*}$ \\
\hline \multirow{3}{*}{ 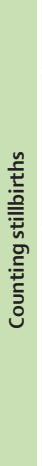 } & $\begin{array}{l}\text { Comparable } \\
\text { definition }\end{array}$ & \multicolumn{3}{|c|}{$\begin{array}{l}\text { All countries should report the definition of } \geq 1000 \mathrm{~g} \text { birthweight or } \geq 28 \text { weeks of gestation for international comparison and the } \\
\text { intrapartum SBR for the same definition of stillbirths }\end{array}$} \\
\hline & Counting priority & $\begin{array}{l}\text { Collection of representative data should be prioritised for } \\
\text { stillbirths } \geq 500 \mathrm{~g} \text { birthweight or at } 22 \text { weeks of gestation, } \\
\text { and those of } \geq 1000 \mathrm{~g} \text { birthweight or at } \geq 28 \text { weeks of } \\
\text { gestation; variants of definitions (eg, } 18 \text { or } 20 \text { weeks) can } \\
\text { be used locally; disparities should be tracked and analysed }\end{array}$ & \multicolumn{2}{|c|}{$\begin{array}{l}\text { Collection of representative data should be prioritised for stillbirths } \\
\text { and intrapartum stillbirths } \geq 1000 \mathrm{~g} \text { birthweight or at } \geq 28 \text { weeks of gestation; } \\
\text { disparities in urban or rural and other key areas should be tracked }\end{array}$} \\
\hline & $\begin{array}{l}\text { Collecting stillbirth } \\
\text { number and } \\
\text { denominator } \\
\text { (total births) }\end{array}$ & $\begin{array}{l}\text { Vital registration should be done with specific stillbirth } \\
\text { or neonatal death certificates with birthweight and } \\
\text { gestational age; health facility surveillance should be } \\
\text { implemented with detailed dataset; vital registration } \\
\text { and health facility databases should be crosslinked to } \\
\text { maximise capture }\end{array}$ & \multicolumn{2}{|c|}{$\begin{array}{l}\text { Large-scale retrospective household surveys should include more } \\
\text { reliable measures of stillbirth (eg, pregnancy history rather than } \\
\text { livebirth history); stillbirth data could be included in MICS surveys; } \\
\text { nationally representative sentinel surveillance sites could be } \\
\text { developed or modified for pregnancy, child, and other health } \\
\text { outcomes (prospective data); vital registration systems should be } \\
\text { improved and stillbirths included; specific stillbirth and neonatal } \\
\text { death certificates should be used }\end{array}$} \\
\hline \multirow{4}{*}{ 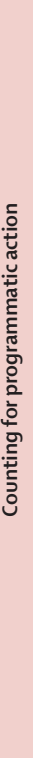 } & $\begin{array}{l}\text { Comparable system } \\
\text { mapping for } \\
\text { antepartum } \\
\text { and intrapartum } \\
\text { stillbirths }\end{array}$ & \multicolumn{3}{|c|}{$\begin{array}{l}\text { Consensus is needed on a limited number of programmatically relevant, comparable causal categories, that can be distinguished } \\
\text { through verbal autopsy, but can be further specified by clinical data in mid-mortality settings and link to complex classification } \\
\text { systems and ICD codes; direct fetal and neonatal causal group and maternal condition should be included to enable cross-reference }\end{array}$} \\
\hline & $\begin{array}{l}\text { Collecting data on } \\
\text { cause and maternal } \\
\text { condition }\end{array}$ & $\begin{array}{l}\text { Data should be collected by vital registration and facility } \\
\text { surveillance; ICD-11 should be used to improve codes for } \\
\text { use for stillbirth and neonatal death; agreement on } \\
\text { standard protocol for pathological investigation of } \\
\text { stillbirth for high-income settings and adaptation for } \\
\text { middle-income settings is needed; detailed causes, focus } \\
\text { on early stillbirth, and growth restriction should be } \\
\text { recorded }\end{array}$ & $\begin{array}{l}\text { Facility audit systems linking maternal, } \\
\text { stillbirth, and neonatal data should be } \\
\text { developed or modified and scaled up; } \\
\text { vital registration coverage and quality } \\
\text { for cause attribution should be improved; } \\
\text { laboratory and other capacities for } \\
\text { investigation should be increased }\end{array}$ & $\begin{array}{l}\text { Data should be collected through } \\
\text { specific verbal autopsy studies } \\
\text { (eg, after household surveys, or in } \\
\text { sentinel surveillance sites); } \\
\text { standard verbal autopsy methods } \\
\text { should be agreed on (eg, simple } \\
\text { case definitions, hierarchical } \\
\text { attribution, link to neonatal } \\
\text { deaths, and maternal conditions) }\end{array}$ \\
\hline & $\begin{array}{l}\text { Assessing and } \\
\text { addressing } \\
\text { avoidable factors }\end{array}$ & $\begin{array}{l}\text { National audit systems should be implemented; } \\
\text { confidential enquiries should be considered; } \\
\text { a committee accountable for follow-up actions } \\
\text { should be linked }\end{array}$ & $\begin{array}{l}\text { Facility audit systems linking maternal, } \\
\text { stillbirth, and neonatal data, and with } \\
\text { accountability mechanisms for action, } \\
\text { should be developed and scaled up }\end{array}$ & $\begin{array}{l}\text { Facility audit in large centres } \\
\text { should be started; specific social } \\
\text { autopsy studies of delays at home, } \\
\text { on the way to hospital, and in } \\
\text { facilities could be implemented }\end{array}$ \\
\hline & Coverage data & $\begin{array}{l}\text { Detailed assessment of coverage and quality of care, } \\
\text { with analyis to target and reduce disparities }\end{array}$ & $\begin{array}{l}\text { Data to track coverage and quality of } \\
\text { antenatal and intrapartum care should } \\
\text { be improved }\end{array}$ & $\begin{array}{l}\text { A few indicators should be } \\
\text { focused on initially, especially } \\
\text { intrapartum and antenatal care } \\
\text { (eg, prevalence, indentification, } \\
\text { and treatment of syphilis) }\end{array}$ \\
\hline
\end{tabular}

Figure 6: Recommendations to improve national stillbirth data

Figure adapted from Lawn and colleagues. ${ }^{75}$ SBR=stillbirth rate. MICS=multiple indicator cluster surveys. ICD-11=International Classification of Diseases, 11 th revision. *Together, these categories constitute $80 \%$ of stillbirths worldwide.

with hospital data, ${ }^{61,62}$ but other studies suggest that verbal autopsy might systematically overestimate the intrapartum proportion. ${ }^{78}$ Categories with enormous public health relevance, such as intrapartum events, might be identified through maternal history in verbal autopsy, but other important causes such as syphilis cannot be recognised in this manner. Advances in verbal autopsy methods and categorisation for neonatal causes of death over the past 5 years have resulted in increased data and improved comparability of data for national estimates, ${ }^{53}$ and the same advances are needed for stillbirth data.

\section{How to reduce numbers of stillbirths}

More reliable data are essential to enhance the effectiveness of health systems to monitor both implementation and effect on stillbirths. Ignoring stillbirths is a missed opportunity to measure effect of programmes for maternal, neonatal, and fetal health. Many of the 350000 maternal deaths every year are associated with lack of effective intrapartum care. Intrapartum stillbirth rates have been proposed as a measure of quality of intrapartum care ${ }^{79}$ and are an important indicator of quality, especially for settings in which maternal deaths are relatively rare. Failure to record stillbirths might also obscure interpretation of changes in early neonatal mortality because a proportion of neonatal deaths might be misclassified as stillbirths. ${ }^{80}$ As obstetric and immediate neonatal care improve, neonatal deaths are less likely to be misclassified as stillbirths. ${ }^{81}$ Population-level planning needs a reliable denominator, which is a challenge in low-income countries 
Overall ranking out of 47

Top five ranked research options for advancing epidemiological understanding of stillbirth

HIV effect on stillbirth

1

Maternal anaemia effect on stillbirth

Malaria effect on stillbirth

3

Maternal syphilis effect on stillbirth

Maternal or obstetric risk factors and prediction of stillbirth

6

Top five ranked research options for advancing epidemiological measurement for stillbirth

Stillbirth classification or mapping system for programmatic decision

making and nationally comparable estimates

Gestational age assessment in surveys

5

Household survey modules and methods for stillbirth measurement

Linking maternal conditions and stillbirth in verbal autopsy data

Demographic surveillance improved methods for stillbirth measurement

9

12

15

16

Priorities are based on scoring of 47 research options by 20 experts. See webappendix pp $15-17$ for list of 47 research options that were scored.

Table 6: Stillbirth epidemiological research priorities for low-income and middle-income countries

where most births are at home. ${ }^{7,82}$ Novel approaches are needed to record pregnancies and outcomes accurately; for example, in India, sentinel surveillance sites are used. ${ }^{83}$

In view of the large differences in stillbirth rates in urban versus rural residences, ethnic origins, and socioeconomic metrics, data for programme design and tracking need to be as local and specific as possible. Even in high-income settings, there are major inequalities in stillbirth rates. For example, in the UK, black women are twice as likely to have an intrapartum stillbirth as are white women. ${ }^{14,84}$ Stillbirth rates have been proposed as a sensitive marker of inequity ${ }^{85}$ and are closely linked to social deprivation, poor maternal health, ${ }^{86}$ and service availability and quality. ${ }^{87}$

Mortality audit is a potentially powerful approach to improve health systems. ${ }^{88}$ Some maternal audits include stillbirths and others could be adapted to incorporate stillbirth and neonatal data. ${ }^{89-91}$ Several examples exist from high-income countries, such as the UK's national enquiries. ${ }^{13}$ There are fewer examples from low-income countries, particularly of a mortality audit on a national scale. In South Africa, there is a voluntary, facility-based audit of stillbirths and neonatal deaths, as well as the confidential enquiry into maternal deaths. ${ }^{92}$ The last step in the audit process (accountability and action) is the most important, although it is often absent, especially on a national scale. ${ }^{71}$

Another important data gap involves indicators for coverage of stillbirth interventions that should be provided during antenatal or intrapartum care. Many of the interventions to reduce stillbirths, such as appropriate management of hypertensive disease in pregnancy, syphilis screening and treatment, ${ }^{93,94}$ or fetal heart rate monitoring, as discussed in the third paper of this Series, ${ }^{20}$ are not routinely tracked at the population level. For women who receive care, there are often missed opportunities between the contact point (antenatal or intrapartum) and the provision of high-impact, evidencebased interventions. A few large-scale assessments of provider skills have been done, and data suggest that service provision might be less effective than expected because of deficiencies in the quality of care. For example, in an assessment of 1358 skilled birth attendants in Nicaragua, the median competency score was only $52 \%$ for five key skills. ${ }^{95,96}$ Although these studies, audits, and routine clinical data are useful for monitoring and addressing deficiencies in quality of care, they are often restricted to specific programme sites, meaning that programme planners do not know the quality of care received by most women and babies. Collection of more data on coverage and quality for individual components within pregnancy and childbirth care is a crucial next step for effective population-level tracking of programmes. ${ }^{97,98}$ DHS includes a detailed module of antenatal care quality; in view of the present overload in DHS survey questions, adding more would be challenging, but a process to review which questions have the most effect and the need to reprioritise the questionnaire is becoming increasingly urgent because of the worldwide dependence on DHS for mortality and coverage data.

\section{Research priorities for stillbirth epidemiology}

Only $3 \%$ of publications on stillbirths were identified to be related to low-income countries in one review, ${ }^{25}$ although these countries accounted for almost $90 \%$ of the burden. This gap is greater than the $10 / 90$ gap for worldwide health research, whereby only $10 \%$ of research addresses $90 \%$ of the burden..$^{99}$ Additionally, there are missed opportunities to include stillbirth outcomes in related studies. In an analysis of Cochrane reviews, ${ }^{54}$ apart from trials on cervical cerclage, only a few pregnancy and intrapartum maternal intervention trials reported stillbirth or neonatal outcomes.

We undertook an exercise to define and rank research questions on improved epidemiological measurement and understanding in low-income and middle-income countries by use of a priority-setting method developed by the Child Health and Nutrition Research Initiative. ${ }^{100,101}$

47 research questions were identified from recent reviews ${ }^{75,02}$ and the GAPPS conference. These questions were refined and scored by 20 experts (webappendix pp 15-17) ${ }^{100}$ for each of the five domains: answerability, effectiveness, deliverability, disease burden reduction, and effect on equity. We report the top five for epidemiological understanding and the top five for advancing epidemiological measurement (table 6). The top ranked questions for advancing epidemiological understanding of stillbirth were dominated by questions on stillbirths and infection, including the relation between stillbirths and HIV infection, malaria, and syphilis (table 6). This finding is logical because, although interventions to address infection in pregnancy are feasible, there are few data on stillbirth as an outcome of 
maternal infections. For example, no high-quality studies of malaria in pregnancy were identified that reported stillbirths. Even syphilis has low-quality data for prevalence in pregnancy, and few studies have an adjusted risk of stillbirth. Other high-ranked epidemiological gaps pertain to maternal anaemia in pregnancy and to prediction of obstetric risk factors. Obstetric risk dominated the development and delivery research agendas for lowincome and middle-income countries after a similar priority-setting exercise in the fourth paper in this Series, ${ }^{21}$ but was not so highly ranked in the epidemiology lists, suggesting that this factor was seen as an implementation research gap rather than an epidemiological understanding gap. Other themes in the top ten epidemiology options included understanding the interaction of infection and hypoxic injury. The research options on epidemiological measurement advances tended to be ranked lower as the effect on disease burden reduction is scored lower. The top ranked option for improving epidemiological measurement was a stillbirth causation mapping system (table 6). More details are published elsewhere. ${ }^{103}$

\section{Conclusions}

Two clear messages resound. First, there are now sufficient data to justify urgent attention and action to reduce this large burden of 2.65 million stillbirths in the last 12 weeks of pregnancy, ${ }^{38}$ linked to about 3 million early neonatal deaths and 350000 maternal deaths. ${ }^{7}$ Stillbirths remain invisible on programmatic and policy priorities and yet are highly relevant to existing investments for maternal and neonatal health, especially for care at the time of birth when a combined 2 million deaths occur (key messages panel). Not counting stillbirths, and especially the 1.2 million that occur during labour, will result in misinterpretation of programme effectiveness. ${ }^{79}$ A new focus on all deaths around the time of birth is crucial for programmatic, research, and data collection system investment to provide a better foundation for prioritising interventions to benefit maternal and neonatal health and to prevent stillbirths.

Second, although there are data to indicate that action is needed now, existing stillbirth data are far from adequate to track trends or programme effectiveness. Having one unified set of worldwide stillbirth estimates is an important short-term step, but improved counting of stillbirths is the real priority. ${ }^{33}$ In the medium-term to long-term, improvements in vital registration, more specific ICD codes, and routine reporting and collation of stillbirth data are crucial, and require leadership within the UN. Immediate advances in worldwide data availability and quality could be achieved through surveys but have not been given attention in recent revisions of the main worldwide survey approaches. Estimates for stillbirth causation are hampered by non-comparable classification systems, yet are necessary to guide programmatic priorities across contexts with varying data complexity including use of verbal autopsy. Facility-based data, especially those collected through national audit systems, are also important (particularly for improving quality of care), but these data need to include stillbirths alongside maternal and neonatal near-misses and deaths, need to be used at scale, and need to result in change. Investment in stillbirth research, even in high-income countries, is low compared with the burden of stillbirths and is almost entirely absent in low-income countries, even in studies that examine maternal or neonatal outcomes. ${ }^{25}$

Millions of families experience stillbirth, yet these deaths remain uncounted, unsupported, and the solutions understudied. Better counting of stillbirths alongside maternal and neonatal deaths and strategic programmatic action will make stillbirths count.

\section{Contributors}

The first draft was written by JEL with inputs from CS and HB. All authors contributed to subsequent drafts. The stillbirth rate and intrapartum stillbirth rate estimates were undertaken by HB and SC with JEL. The analysis for South Africa was undertaken by RP with JEL and the analysis for high-income countries by J Fredrik Frøen and Vicki Flenady. The research priority setting was designed and coordinated by JEL and analysis undertaken by II.

The Lancet's Stillbirths Series steering committee

J Fredrik Frøen, Joy E Lawn, Zulfiqar A Bhutta, Robert Pattinson, Vicki Flenady, Robert L Goldenberg, and Monir Islam.

\section{Conflicts of interest}

We declare that we have no conflicts of interest.

\section{Acknowledgments}

Some of the technical work for this paper during 2010 was funded through a grant from the Bill \& Melinda Gates Foundation to the International Stillbirth Alliance secretariat for this series. JEL is funded by the Bill \& Melinda Gates Foundation via Saving Newborn Lives/Save the Children. CS was partly funded by the Global Alliance to Prevent Prematurity and Stillbirth. The views expressed herein are solely those of the authors. We thank the team involved in the stillbirth rate estimates (Doris Chou, Saifuddin Ahmed, Laura Steinhardt, Andreea A Creanga, Özge Tuncalp, Zohra Patel Balsara, Shivam Gupta, and Lale Say); Vicki Flenady, J Frederik Frøen, and their team for the stillbirth cause and condition data from high-income countries; Felicity Mussell as the perinatal audit coordinator at LAMB Hospital, Bangladesh;

Mikkel Oestergaard and Florence Rusciano at WHO for assistance with figure 2, the 20 scorers for the CHNRI research priority setting exercise (Romano Byaruhanga, Hannah Blencowe, Simon Cousens,

Gary L Darmstadt, Louise T Day, Karen Edmond, Vincent Fauveau, Alfredo Fort, J Frederik Frøen, Ron Gray, Rachel Haws, G Justus Hofmeyr, Jane Hirst, Mary Kamb, Anne C C Lee, Elizabeth M McClure, Nafissa Bique Osman, Robert Pattinson, Sonia Lansky, and Dave Woods); and J Frederik Frøen for contributing to an earlier draft of this report.

\section{References}

1 Black RE, Morris SS, Bryce J. Where and why are 10 million children dying every year? Lancet 2003; 361: 2226-34.

2 Rohde J, Cousens S, Chopra M, et al. 30 years after Alma-Ata: has primary health care worked in countries? Lancet 2008; 372: 950-61.

3 Ronsmans C, Graham WJ. Maternal mortality: who, when, where, and why. Lancet 2006; 368: 1189-200.

4 Rosenfield A, Maine D. Maternal mortality-a neglected tragedy. Where is the M in MCH? Lancet 1985; 2: 83-85.

5 Shiffman J. Issue attention in global health: the case of newborn survival. Lancet 2010; 375: 2045-49.

6 Knippenberg R, Lawn JE, Darmstadt GL, et al. Systematic scaling up of neonatal care in countries. Lancet 2005; 365: 1087-98.

7 Lawn JE, Cousens S, Zupan J. 4 million neonatal deaths: When? Where? Why? Lancet 2005; 365: 891-900.

8 Frøen JF, Cacciatore J, McClure EM, et al, for The Lancet's Stillbirths Series steering committee. Stillbirths: why they matter. Lancet 2011; published online April 14. DOI:10.1016/S0140-6736(10)62232-5. 
9 Rajaratnam JK, Marcus JR, Flaxman AD, et al. Neonatal, postneonatal, childhood, and under- 5 mortality for 187 countries, 1970-2010: a systematic analysis of progress towards Millennium Development Goal 4. Lancet 2010; 375: 1988-2008.

10 Kramer MS, Liu S, Luo Z, Yuan H, Platt RW, Joseph KS. Analysis of perinatal mortality and its components: time for a change? Am J Epidemiol 2002; 156: 493-97.

11 Ananth CV, Liu S, Joseph KS, Kramer MS. A comparison of foetal and infant mortality in the United States and Canada. Int J Epidemiol 2009; 38: 480-89.

12 MacDorman MF, Kirmeyer S. Fetal and perinatal mortality, United States, 2005. Natl Vital Stat Rep 2009; 57: 1-19.

13 Centre for Maternal and Child Enquiries. Perinatal mortality 2008. http://www.cemach.org.uk/getattachment/60bc0b7b-e304-4836-a5e726895c97ab20/Perinatal-Mortality-2008.aspx (accessed Jan 7, 2011).

14 Flenady V, Koopmans L, Middleton P, et al. Major risk factors for stillbirth in high-income countries: a systematic review and meta-analysis. Lancet 2011; published online April 14. DOI:10.1016/ S0140-6736(10)62233-7.

15 Smith GC, Fretts RC. Stillbirth. Lancet 2007; 370: 1715-25.

16 Stanton C, Lawn JE, Rahman H, Wilczynska-Ketende K, Hill K. SBRs: delivering estimates in 190 countries. Lancet 2006; 367: 1487-94.

17 WHO. Perinatal and neonatal mortality for the year 2000: country, regional and global estimates. Geneva: World Health Organization, 2006.

18 Shiffman J. Generating political priority for safe motherhood. Afr J Reprod Health 2004; 8: 6-10.

19 Pitt C, Greco G, Powell-Jackson T, Mills A. Countdown to 2015: assessment of official development assistance to maternal, newborn, and child health, 2003-08. Lancet 2010 371: 1268-75.

20 Bhutta ZA, Yakoob MY, Lawn JE, et al, for The Lancet's Stillbirths Series steering committee. Stillbirths: what difference can we make and at what cost? Lancet 2011; published online April 14. DOI:10.1016/ S0140-6736(10)62050-8.

21 Pattinson R, Kerber K, Buchmann E, et al, for The Lancet's Stillbirths Series steering committee. Stillbirths: how can health systems deliver for mothers and babies? Lancet 2011; published online April 14. DOI:10.1016/S0140-6736(10)62306-9.

22 Woods R. Long-term trends in fetal mortality: implications for developing countries. Bull World Health Organ 2008; 86: 460-66.

23 Woods R. Death before birth 2009. Oxford University Press, 2009: 294.

24 WHO. International statistical classification of diseases and related health problems: tenth revision, volume 2: instruction manual. Geneva: World Health Organization, 1993.

25 Froen JF, Gordijn SJ, Abdel-Aleem H, et al. Making stillbirths count, making numbers talk-issues in data collection for stillbirths. BMC Pregnancy Childbirth 2009; 9: 58.

26 Yasmin S, Osrin D, Paul E, Costello A. Neonatal mortality of low-birth-weight infants in Bangladesh. Bull World Health Organ 2001; 79: 608-14.

27 Lawn JE, Mwansa-Kambafwile J, Horta BL, Barros FC, Cousens S 'Kangaroo mother care' to prevent neonatal deaths due to preterm birth complications. Int J Epidemiol 2010; 39 (suppl 1): i144-54.

28 Wood NS, Costeloe K, Gibson AT, Hennessy EM, Marlow N, Wilkinson AR. The EPICure study: growth and associated problems in children born at 25 weeks of gestational age or less. Arch Dis Child Fetal Neonatal Ed 2003; 88: F492-500.

29 Costeloe K, Hennessy E, Gibson AT, Marlow N, Wilkinson AR. The EPICure study: outcomes to discharge from hospital for infants born at the threshold of viability. Pediatrics 2000; 106: 659-71.

30 Costeloe K. EPICure: facts and figures: why preterm labour should be treated. BJOG 2006; 113 (suppl 3): 10-12.

31 Critical care decisions in fetal and neonatal medicine: ethical issues. Nuffield Council on Bioethics, 2006. http://www.nuffieldbioethics. org/neonatal-medicine (accessed Jan 7, 2011).

32 Macfarlane A, Gissler M, Bolumar F, Rasmussen S. The availability of perinatal health indicators in Europe. Eur J Obstet Gynecol Reprod Biol 2003; 111 (suppl 1): S15-32.

33 Gissler M, Mohangoo AD, Blondel B, et al. Perinatal health monitoring in Europe: results from the EURO-PERISTAT project. Inform Health Soc Care 2010; 35: 64-79.
34 Goldenberg RL, McClure EM. Reducing intrapartum stillbirths and intrapartum-related neonatal deaths. Int J Gynaecol Obstet 2009; 107 (suppl 1): S1-3.

35 Edouard L. The epidemiology of perinatal mortality. World Health Stat Q 1985; 38: 289-301.

36 WHO. Perinatal mortality: a listing of available information. Geneva: World Health Organization/FRH/MSM/96.7, 1996.

37 Say L, Donner A, Gulmezoglu AM, Taljaard M, Piaggio G. The prevalence of stillbirths: a systematic review. Reprod Health 2006; 3: 1.

38 Cousens S, Stanton C, Blencowe H, et al. National, regional, and worldwide estimates of stillbirth rates in 2009 with trends since 1995: a systematic analysis. Lancet 2011; published online April 14 DOI:10.1016/S0140-6736(10)62310-0.

39 Lawn JE, Kerber K, Enweronu-Laryea C, Cousens S. 3.6 million neonatal deaths-what is progressing and what is not? Semin Perinatol 2010; 34: 371-86.

40 Black RE, Cousens S, Johnson HL, et al. Global, regional, and national causes of child mortality in 2008: a systematic analysis. Lancet 2010; 375: 1969-87.

41 WHO, UNICEF UNFPA, World Bank. Trends in maternal mortality: 1990 to 2008. http://www.who.int/reproductivehealth/publications/ monitoring/9789241500265/en/index.html (accessed Jan 7, 2011).

42 Bhutta Z, Nundy S, Abbasi K. Is there hope for South Asia? BMJ 2004; 328: 777-78.

43 Bang AT, Bang RA, Baitule SB, Reddy MH, Deshmukh MD. Effect of home-based neonatal care and management of sepsis on neonatal mortality: field trial in rural India. Lancet 1999; 354: 1955-61.

44 Akpala CO. Perinatal mortality in a northern Nigerian rural community. J R Soc Health 1993; 113: 124-27.

45 Aisien AO, Lawson JO, Okolo A. Two years prospective study of perinatal mortality in Jos, Nigeria. Int J Grnaecol Obstet 2000 71: 171-73.

46 Wu Z, Viisainen K, Wang Y, Hemminki E. Perinatal mortality in rural China: retrospective cohort study. BMJ 2003; 327: 1319.

47 Wang H, Yuan X, Yan S. Monitoring and intervention of infant mortality rate and fetal and infant mortality rate in Beijing, 1992-2000. Zhonghua Yi Xue Za Zhi 2001; 81: 1424-26.

48 Countdown. Countdown to 2015 decade report: taking stock of maternal, newborn and child survival. Geneva: World Health Organization, 2010.

49 Lawn JE, Lee AC, Kinney M, et al. Two million intrapartum-related stillbirths and neonatal deaths: where, why, and what can be done? Int J Gynaecol Obstet 2009; 107 (suppl 1): S5-18.

50 Lawn J, Shibuya K, Stein C. No cry at birth: global estimates of intrapartum stillbirths and intrapartum-related neonatal deaths. Bull World Health Organ 2005; 83: 409-17.

51 Maternal and Child Health Research Consortium. Confidential Enquiry into Stillbirths and Deaths in Infancy (CESDI). 7th annual report. London: Maternal and Child Health Research Consortium, 1999.

52 Li XF, Fortney JA, Kotelchuck M, Glover LH. The postpartum period: the key to maternal mortality. Int J Gynaecol Obstet 1996; 54: 1-10.

53 Lawn JE, Wilczynska-Ketende K, Cousens SN. Estimating the causes of 4 million neonatal deaths in the year 2000. Int J Epidemiol 2006; 35: 706-18

54 Lawn JE, Yakoob MY, Haws RA, Soomro T, Darmstadt GL, Bhutta ZA. 3.2 million stillbirths: epidemiology and overview of the evidence review. BMC Pregnancy Childbirth 2009; 9 (suppl 1): S2.

55 Korteweg FJ, Gordijn SJ, Timmer A, et al. The Tulip classification of perinatal mortality: introduction and multidisciplinary inter-rater agreement. BJOG 2006; 113: 393-401.

56 Flenady V, Froen JF, Pinar H, et al. An evaluation of classification systems for stillbirth. BMC Pregnancy Childbirth 2009; 9: 24.

57 Gardosi J, Kady SM, McGeown P, Francis A, Tonks A. Classification of stillbirth by relevant condition at death (ReCoDe): population based cohort study. BMJ 2005; 331: 1113-17.

58 Froen JF, Gardosi JO, Thurmann A, Francis A, Stray-Pedersen B. Restricted fetal growth in sudden intrauterine unexplained death. Acta Obstet Gynecol Scand 2004; 83: 801-07.

59 Vergani P, Cozzolino S, Pozzi E, et al. Identifying the causes of stillbirth: a comparison of four classification systems. Am J Obstet Gynecol 2008; 199: 319 e1-4. 
60 Campbell O, Gipson R, el-Mohandes A, et al. The Egypt national perinatal/neonatal mortality study 2000. J Perinatol 2004; 24: 284-89.

61 Edmond KM, Quigley MA, Zandoh C, et al. Aetiology of stillbirths and neonatal deaths in rural Ghana: implications for health programming in developing countries. Paediatr Perinat Epidemiol 2008; 22: 430-37.

62 Edmond KM, Quigley MA, Zandoh C, et al. Diagnostic accuracy of verbal autopsies in ascertaining the causes of stillbirths and neonatal deaths in rural Ghana. Paediatr Perinat Epidemiol 2008; 22: 417-29.

63 Oyelese KO, Black RS, Lees CC, Campbell S. A novel approach to the management of pregnancies complicated by uteroplacenta insufficiency and previous stillbirth. Aust N Z J Obstet Gynaecol 1998; 38: 391-95.

64 Winbo IG, Serenius FH, Dahlquist GG, Kallen BA. A computer-based method for cause of death classification in stillbirths and neonatal deaths. Int J Epidemiol 1997; 26: 1298-306.

65 Winbo IG, Serenius FH, Dahlquist GG, Kallen BA. NICE, a new cause of death classification for stillbirths and neonatal deaths. Neonatal and Intrauterine Death Classification according to Etiology. Int J Epidemiol 1998; 27: 499-504.

66 Froen JF, Arnestad M, Frey K, Vege A, Saugstad OD, Stray-Pedersen B. Risk factors for sudden intrauterine unexplained death: epidemiologic characteristics of singleton cases in Oslo, Norway, 1986-1995. Am J Obstet Gynecol 2001; 184: 694-702.

67 Huang DY, Usher RH, Kramer MS, Yang H, Morin L, Fretts RC. Determinants of unexplained antepartum fetal deaths. Obstet Gynecol 2000; 95: 215-21.

68 Petersson K, Bremme K, Bottinga R, et al. Diagnostic evaluation of intrauterine fetal deaths in Stockholm 1998-99. Acta Obstet Gynecol Scand 2002; 81: 284-92.

69 Ticconi C, Mapfumo M, Dorrucci M, et al. Effect of maternal HIV and malaria infection on pregnancy and perinatal outcome in Zimbabwe. J Acquir Immune Defic Syndr 2003; 34: 289-94.

70 Goldenberg RL, McClure EM, Saleem S, Reddy UM. Infection-related stillbirths. Lancet 2010; 375: 1482-90.

71 Pattinson R, Kerber K, Waiswa P, et al. Perinatal mortality audit: counting, accountability, and overcoming challenges in scaling up in low- and middle-income countries. Int J Gynaecol Obstet 2009; 107 (suppl 1): S113-22.

72 Medical Research Council Maternal and Infant Health Care Strategies Research Unit. Saving babies 2008-2009: seventh perinatal care survey of South Africa. Pretoria, South Africa: Tshepesa Press (in press).

73 Hogan MC, Foreman KJ, Naghavi M, et al. Maternal mortality for 181 countries, 1980-2008: a systematic analysis of progress towards Millennium Development Goal 5. Lancet 2010; 375: 1609-23.

74 Hill K, Thomas K, AbouZahr C, et al. Estimates of maternal mortality worldwide between 1990 and 2005: an assessment of available data. Lancet 2007; 370: 1311-19.

75 Lawn JE, Gravett MG, Nunes TM, Rubens CE, Stanton C. Global report on preterm birth and stillbirth (1 of 7): definitions, description of the burden and opportunities to improve data. BMC Pregnancy Childbirth 2010; 10 (suppl 1): S1.

76 AbouZahr C, Cleland J, Coullare F, et al. The way forward. Lancet 2007; 370: 1791-99.

77 Hill K, Lopez AD, Shibuya K, Jha P. Interim measures for meeting needs for health sector data: births, deaths, and causes of death. Lancet 2007; 370: 1726-35.

78 Aggarwal A, Jain V, Kumar R. Validity of verbal autopsy for ascertaining the causes of stillbirth. Bull World Health Organ 2011; 89: $31-40$.

79 Fauveau V. New indicator of quality of emergency obstetric and newborn care. Lancet 2007; 370: 1310.

80 Spector JM, Daga S. Preventing those so-called stillbirths. Bull World Health Organ 2008; 86: 315-16.

81 Barson AJ, Tasker M, Lieberman BA, Hillier VF. Impact of improved perinatal care on the causes of death. Arch Dis Child 1984 59: 199-207.

82 Lawn JE, Osrin D, Adler A, Cousens S. Four million neonatal deaths: counting and attribution of cause of death. Paediatr Perinat Epidemiol 2008; 22: 410-16.
83 Jha P, Gajalakshmi V, Gupta PC, et al. Prospective study of one million deaths in India: rationale, design, and validation results. PLoS Med 2006; 3: e18.

84 Acolet D. Perinatal mortality, England, Wales and Northern Ireland, 2006. 7th annual report. London: Confidential Enquiry into Maternal and Child Health, 2008. http://cmace-legacy.interface-dev. com/getattachment/4cc984be-9460-4cc7-91f1-532c9424f76e/PerinatalMortality-2006.aspx (accessed Jan 7, 2011).

85 Parsons L, Duley L, Alberman E. Socio-economic and ethnic factors in stillbirth and neonatal mortality in the NE Thames Regional Health Authority (NETRHA) 1983. Br J Obstet Gynaecol 1990; 97: $237-44$.

86 Luo ZC, Wilkins R, Kramer MS. Effect of neighbourhood income and maternal education on birth outcomes: a population-based study. CMAJ 2006 May 9; 174: 1415-20.

87 David RJ, Siegel E. Decline in neonatal mortality, 1968 to 1977: better babies or better care? Pediatrics 1983; 71: 531-40.

88 Shankar A, Bartlett L, Fauveau V, Islam M, Terreri N. Delivery of MDG 5 by active management with data. Lancet 2008; 371: 1223-24.

89 Langhoff-Roos J, Borch-Christensen H, Larsen S, Lindberg B, Wennergren M. Potentially avoidable perinatal deaths in Denmark and Sweden 1991. Acta Obstet Gynecol Scand 1996; 75: 820-25.

90 Pattinson RC, Makin JD, Shaw A, Delport SD. The value of incorporating avoidable factors into perinatal audits. S Afr Med J 1995; 85: $145-47$.

91 Ward HR, Howarth GR, Jennings OJ, Pattinson RC. Audit incorporating avoidability and appropriate intervention can significantly decrease perinatal mortality. S Afr Med J 1995; 85: 147-50.

92 Bradshaw D, Chopra M, Kerber K, et al. Every death counts: use of mortality audit data for decision making to save the lives of mothers, babies, and children in South Africa. Lancet 2008 371: 1294-304.

93 Rani M, Bonu S, Harvey S. Differentials in the quality of antenatal care in India. Int J Qual Health Care 2008; 20: 62-71.

94 Lawn JE, Kerber K. Opportunities for Africa's newborns: practical data, policy and programmatic support for newborn care in Africa. http://www.healthynewbornnetwork.org/resource/opportunitiesafricas-newborns (accessed Jan 7, 2011)

95 Harvey SA, Ayabaca P, Bucagu M, et al. Skilled birth attendant competence: an initial assessment in four countries, and implications for the Safe Motherhood movement. Int J Gynaecol Obstet 2004; 87: 203-10.

96 Harvey SA, Blandon YC, McCaw-Binns A, et al. Are skilled birth attendants really skilled? A measurement method, some disturbing results and a potential way forward. Bull World Health Organ 2007; 85: 783-90.

97 Bryce J, Daelmans B, Dwivedi A, et al. Countdown to 2015 for maternal, newborn, and child survival: the 2008 report on tracking coverage of interventions. Lancet 2008; 371: 1247-58.

98 Lawn JE, Kinney M, Lee AC, et al. Reducing intrapartum-related deaths and disability: can the health system deliver? Int J Gynaecol Obstet 2009; 107 (suppl 1): S123-32.

99 Doyal L. Gender and the 10/90 gap in health research. Bull World Health Organ 2004; 82: 162.

100 Rudan I, Gibson J, Kapiriri L, et al. Setting priorities in global child health research investments: assessment of principles and practice. Croat Med J 2007; 48: 595-604.

101 Child Health and Nutrition Research Initiative. http://www.chnri.org (accessed Jan 11, 2011).

102 Global Alliance to Prevent Prematurity and Stillbirth. Global report on preterm birth and stillbirth: the foundation for innovative solutions and improved outcomes. BMC Pregnancy Childbirth 2010; 10 (suppl 1): S7.

103 Stillbirth Research Consortium. A global research agenda to reduce stillbirth. 2010. Panel presentation. International Stillbirth Alliance, Sydney, October, 2010. http://www.isaispid2010.com (accessed March 16, 2011). 